\title{
Ultrafast Spectroscopic and Matrix Isolation Studies of p-Biphenylyl, o-Biphenylyl, and 1-Naphthylnitrenium Cations
}

\author{
Jin Wang, ${ }^{\dagger}$ Gotard Burdzinski, ${ }^{\ddagger}$ Zhendong Zhu, ${ }^{\dagger}$ Matthew S. Platz, ${ }^{*},{ }^{\dagger}$ \\ Claudio Carra,, and Thomas Bally ${ }^{*} \S$ \\ Contribution from the Department of Chemistry, The Ohio State University, 100 West 18th \\ Avenue, Columbus, Ohio, 43210, Quantum Electronics Laboratory, Faculty of Physics, Adam \\ Mickiewicz University, 85 Umultowska, Poznan 61-614, Poland, and Département de Chimie, \\ Université de Fribourg, Chemin du Musée 9, CH-1700 Fribourg, Switzerland
}

\begin{abstract}
Biphenylyl, o-biphenylyl, and 1-naphthyl azides were deposited in argon at low temperature in the presence and absence of $\mathrm{HCl}$. In the absence of $\mathrm{HCl}$, the known electronic and vibrational spectra of the corresponding triplet nitrenes, azirines, and didehydroazepines were observed, whereas in the presence of $\mathrm{HCl}$, photolysis of these azides produces new electronic spectra assigned to the corresponding nitrenium cations. For $p$-biphenylyl azide the resulting spectrum of the nitrenium ion is very similar to the previously observed solution-phase spectrum of this species. The vibrational spectrum of this cation was recorded for the first time. Spectroscopic evidence for the previously unknown o-biphenylylnitrenium cation and 1 -naphthylnitrenium cation are provided. The spectra of $p$ - and $o$-biphenylylnitrenium cations and 1-naphthylnitrenium cation are well reproduced by CASSCF and CASPT2 calculations. The same nitrenium cations were detected in solution by femtosecond time-resolved laser flash photolysis of the appropriate azides in $88 \%$ formic acid. The transient spectra of the nitrenium cations recorded in solution are in good agreement with the spectra obtained in $\mathrm{HCl}$ matrices. The rates of formation of these cations equal the rates of decay of the singlet nitrenes in $88 \%$ formic acid and are as follows: $p$-biphenylyl $\left(\tau_{\text {growth }}=11.5\right.$ ps), o-biphenylyl ( $\left.\tau_{\text {growth }}=7.7 \mathrm{ps}\right)$, and 1-naphthylnitrenium cations $\left(\tau_{\text {growth }}=8.4 \mathrm{ps}\right)$. The decay lifetimes of $p$ - and $o$-biphenylylnitrenium cations are 50 and $27 \mathrm{~ns}$, respectively. The decay lifetimes of 1-naphthylnitrenium cation is 860 ps in $88 \%$ formic acid.
\end{abstract}

\section{Introduction}

Arylnitrenium cations and their conjugate bases, arylnitrenes, are reactive intermediates of fundamental importance. ${ }^{1-5}$ Arylnitrenium cations form covalent adducts with the guanine residues of DNA by a typical electrophilic aromatic substitution process. ${ }^{6,7}$ The formation of these adducts can be correlated with the carcinogenic activity of aryl amines. ${ }^{8,9}$

Arylnitrenes, which have a quite unique electronic structure, are important intermediates in synthetic organic chemistry and in the attachment of small, highly functionalized molecules to biomolecules and synthetic polymers. ${ }^{10-12}$

\footnotetext{
$\dagger$ The Ohio State University.

Adam Mickiewicz University.

§ Université de Fribourg.

(1) Davidse, P. A.; Kahley, M. J.; McClelland, R. A.; Novak, M. J. Am. Chem. Soc. 1994, 116, 4513-4514.

(2) McClelland, R. A.; Davidse, P. A.; Hadzialic, G. J. Am. Chem. Soc. 1995, 117, 4173-4174.

(3) McClelland, R. A. Tetrahedron 1996, 52, 6823-6858.

(4) McClelland, R. A.; Kahley, M. J.; Davidse, P. A.; Hadzialic, G. J. Am. Chem. Soc. 1996, 118, 4794-4803.

(5) Falvey, D. E. In Reactive Intermediate Chemistry; Moss, R. A., Platz, M. S., Jones, M., Eds.; John Wiley \& Sons, Inc.: Hoboken, NJ, 2004; pp 593-650.

(6) McClelland, R. A.; Ahmad, A.; Dicks, A. P.; Licence, V. E. J. Am. Chem. Soc. 1999, 121, 3303-3310.

(7) Cheng, B.; McClelland, R. A. Can. J. Chem. 2001, 79, 1881-1886.

(8) Miller, J. A. Cancer Res. 1970, 30, 559-576.

(9) Miller, E. C. Cancer Res. 1978, 38, 1479-1496.
}

The understanding of arylnitrenes developed more rapidly than that of nitrenium cations, mainly due to a lack of convenient precursors for the latter. Aryl azides are readily available, and the photolysis of parent phenyl azide leads to the production of singlet nitrene ${ }^{\mathbf{1}} \mathbf{1}$, benzazirine $\mathbf{2}$, didehydroazepine $\mathbf{3}$, and triplet nitrene ${ }^{\mathbf{3}} \mathbf{1}$ (Scheme 1). These types of reactive intermediates have been characterized by several physical techniques including flash photolysis in solution phase with UV-vis and IR detection and matrix isolation EPR, IR, UV-vis, and emission spectroscopy. ${ }^{10-12}$

In recent years, the groups of Falvey, ${ }^{13-16}$ McClelland, ${ }^{1-4}$ and Novak ${ }^{17-22}$ have developed convenient precursors for

(10) Gritsan, N. P.; Platz, M. S. Chem. Rev. 2006, 106, 3844-3867.

(11) Pritchina, E. A.; Gritsan, N. P.; Bally, T. Phys. Chem. Chem. Phys. 2006, 8, 719-727.

(12) Carra, C.; Nussbaum, R.; Bally, T. Chem. Phys. Chem. 2006, 7, 12681275 .

(13) Anderson, G. B.; Falvey, D. E. J. Am. Chem. Soc. 1993, 115, 9870-9871.

(14) Robbins, R. J.; Yang, L. L. N.; Anderson, G. B.; Falvey, D. E. J. Am. Chem. Soc. 1995, 117, 6544-6552.

(15) Srivastava, S.; Falvey, D. E. J. Am. Chem. Soc. 1995, 117, 10186-10193.

(16) Kung, A. C.; Falvey, D. E. J. Org. Chem. 2005, 70, 3127-3132.

(17) Novak, M.; Kahley, M. J.; Eiger, E.; Helmick, J. S.; Peters, H. E. J. Am. Chem. Soc. 1993, 115, 9453-9460.

(18) Novak, M.; Kahley, M. J.; Lin, J.; Kennedy, S. A.; Swanegan, L. A. J. Am. Chem. Soc. 1994, 116, 11626-11627.

(19) Novak, M.; Kennedy, S. A. J. Am. Chem. Soc. 1995, 117, 574-575.

(20) Novak, M.; Kazerani, S. J. Am. Chem. Soc. 2000, 122, 3606-3616.

(21) Novak, M.; Rajagopal, S. Adv. Phys. Org. Chem. 2001, 36, 167-254.

(22) Novak, M.; Rajagopal, S. Chem. Res. Toxicol. 2002, 15, 1495-1503. 
Scheme 1

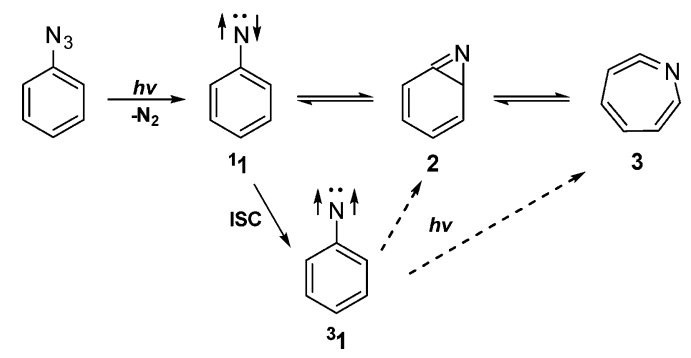

studying the solution-phase chemistry of nitrenium cations, which allowed the measurement of their lifetimes, the determination of their UV-vis and IR spectra, and the determination of rate constants for reactions with selected nucleophiles, in aqueous solution. In the early 1990s, Falvey's group reported the first laser flash photolysis (LFP) study on nitrenium cations, which they obtained by photoisomerization of anthranilium cations, ${ }^{13}$ i.e., precursors that inherently carry a carbonyl group on the aromatic ring. Later, they developed more general photochemical precursors such as $N$-aminopyridinium cations. ${ }^{13-15,23,24}$

In principle, any nitrenium cation can be generated from such precursors, but monosubstituted $\mathrm{N}$-aminopyridinium cations ( pyr $^{+-}$NHR) are unstable. The most convenient way to generate monosubstituted nitrenium cations, $\mathrm{RNH}^{+}$, was developed by McClelland et al. who photolyzed aryl azides in water to generate singlet nitrenes, which are subsequently protonated to form nitrenium cations. ${ }^{1-4}$ This method works particularly well when the singlet nitrene to be intercepted has a relatively long lifetime (>10 ns) in aprotic solvent at ambient temperatures. In this manner, $p$-biphenylylnitrenium cation $\mathbf{6}$, produced by protonation of nitrene $\mathbf{5}$, was readily detected by transient UVvis spectroscopy (Scheme 2). ${ }^{1-4}$ Zhu et al. subsequently studied this nitrenium cation in water using time-resolved resonance Raman spectroscopy and assigned the spectra with the aid of DFT calculations. ${ }^{25}$

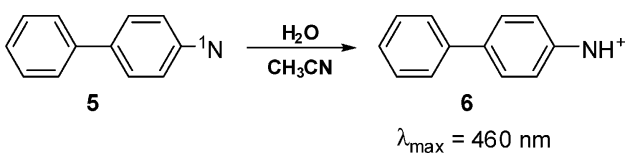

Similarly, Michalak et al. produced fluorinated arylnitrenium cations in acidic acetonitrile solution by flash photolysis of the corresponding aryl azides. ${ }^{26}$

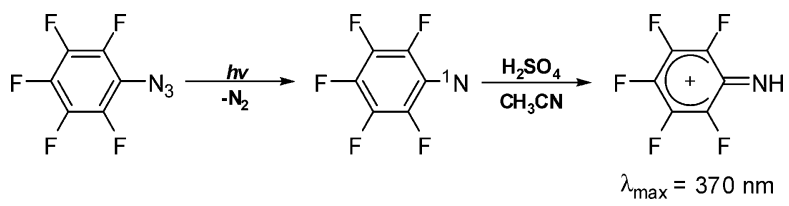

Although product studies indicate that the parent singlet phenylnitrene ( $\tau \approx 1 \mathrm{~ns}$, organic solvents) can also be protonated in acidic aqueous solution, LFP studies failed to produce the

(23) Srivastava, S.; Toscano, J. P.; Moran, R. J.; Falvey, D. E. J. Am. Chem. Soc. 1997, 119, 11552-11553.

(24) Srivastava, S.; Ruane, P. H.; Toscano, J. P.; Sullivan, M. B.; Cramer, C. J.; Chiapperino, D.; Reed, E. C.; Falvey, D. E. J. Am. Chem. Soc. 2000, $122,8271-8278$

(25) Zhu, P.; Ong, S. Y.; Chan, P. Y.; Poon, Y. F.; Leung, K. H.; Phillips, D. L. Chem. Eur. J. 2001, 7, 4928-4936.

(26) Michalak, J.; Zhai, H. B.; Platz, M. S. J. Phys. Chem. 1996, 100, $14028-$ 14036. transient spectrum of the phenylnitrenium cation.,27 From competition studies its lifetime was estimated to be $\sim 30 \mathrm{ps,}$ which is too short to allow its observation by nanosecond spectroscopy. Thus, ultrafast time-resolved techniques are necessary to directly observe certain nitrenium ions in solution.

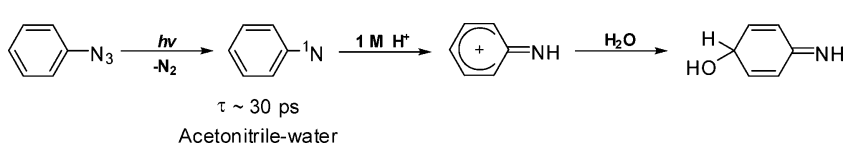

The intrinsic drawback of McClelland's method is that the protonation of the singlet nitrene has to be rapid enough to compete with its other deactivation channels, such as intersystem crossing to the lower energy triplet state and intramolecular rearrangement (see Scheme 1).

$o$-Biphenylylnitrene $\mathbf{8}$ and 1-naphthylnitrene $\mathbf{1 5}$ are wellknown short-lived singlet nitrenes, whose lifetimes in $\mathrm{CH}_{3} \mathrm{CN}$ (16 and 12 ps, respectively $)^{28,29}$ are controlled by intramolecular cyclizations (Schemes 3 and 4). Thus, even if protonation can compete with the other decay channels, ultrafast spectroscopic methods would be required to resolve the formation of these nitrenium cations.

A number of nitrenium cations have been characterized by transient absorption spectroscopy experiments, and a good deal has been learned about their lifetimes and rate constants for reactions with other species. However, there are few direct experimental measurements of the structure of these short-lived species. Time-resolved infrared absorption spectroscopy (TRIR) experiments have recently been used to obtain vibrational spectra of several nitrenium cations, generated by flash photolysis of aminopyridinium salts. The first such study confirmed that the diphenylnitrenium cation has an iminocyclohexadienyl cationlike structure. ${ }^{24}$

The lifetimes of singlet arylnitrenes are temperature dependent. At low temperatures the thermally activated intramolecular rearrangements become slow, and singlet nitrene lifetimes increase to $\sim 100 \mathrm{~ns}$ and are limited by intersystem crossing to the lower energy triplet state (cf., Schemes 1-4). This led us to hypothesize that photolysis of aryl azides in $\operatorname{argon} / \mathrm{HCl}$ matrices might lead to efficient capture of singlet nitrenes and produce nitrenium cations that are persistent under the conditions of matrix isolation, which would allow their convenient spectroscopic analysis. Also, matrix conditions lead to higher resolution spectra of molecules than those that can be obtained in solution, particularly in the case of vibrational spectroscopy. ${ }^{30}$

In this study, we will apply ultrafast UV-vis spectroscopy to study reaction rates and mechanisms, complemented by matrix isolation spectroscopy, to collect structural information. As a first substrate in these experiments, we choose p-biphenylyl azide 4 because both the corresponding nitrene $\mathbf{5}^{28,29}$ and the expected nitrenium cation $\mathbf{6}^{2,4}$ (Scheme 2) are well characterized. We will then proceed to extend this approach to $o$-biphenylyl azide 7 and 1-naphthyl azide 14 which produce short-lived singlet arylnitrenes and hitherto unknown nitrenium cations.

(27) Fishbein, J. C.; McClelland, R. A. Can. J. Chem. 1996, 74, 1321-1328.

(28) Burdzinski, G. T.; Gustafson, T. L.; Hackett, J. C.; Hadad, C. M.; Platz, M. S. J. Am. Chem. Soc. 2005, 127, 13764-13765.

(29) Burdzinski, G.; Hackett, J. C.; Wang, J.; Gustafson, T. L.; Hadad, C. M.; Platz, M. S. J. Am. Chem. Soc. 2006, 128, 13402-13411.

(30) Hayes, J. C.; Sheridan, R. S. J. Am. Chem. Soc. 1990, 112, 5879-5881. 
Scheme 2

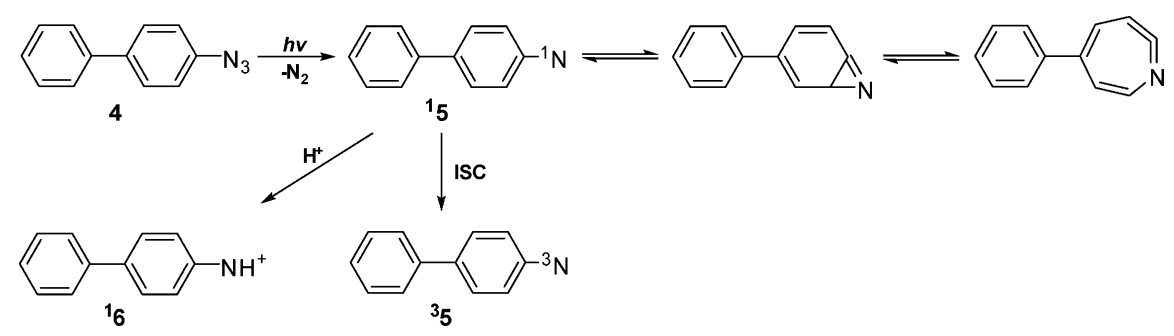

Scheme 3

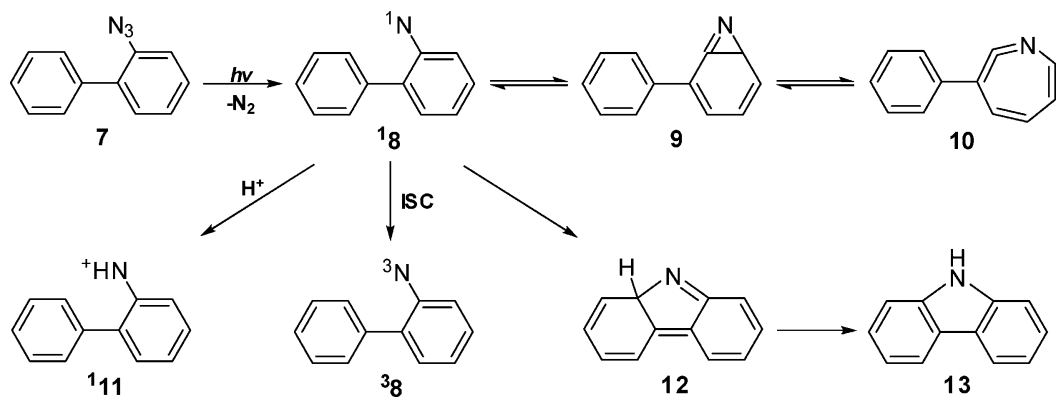

Scheme 4

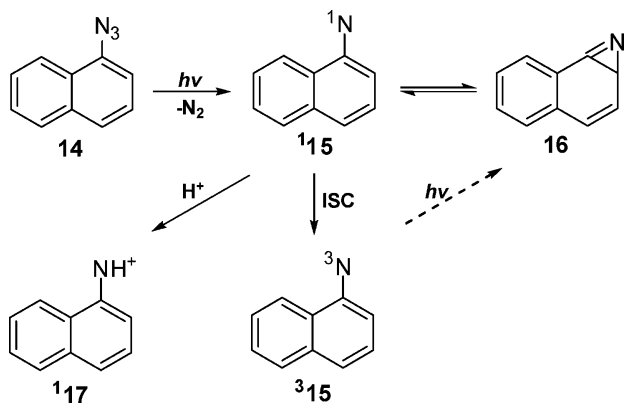

\section{Results and Discussion}

\section{1. $p$-Biphenylylnitrenium Cation.}

2.1.1. Ultrafast Spectroscopy. Ultrafast LFP $(270 \mathrm{~nm})$ of $p$-biphenylyl azide in a mixture of 50\% water and 50\% acetonitrile produces the spectra shown in Figure 1. A transient absorption band centered at $350 \mathrm{~nm}$, which is assigned to singlet $p$-biphenylylnitrene $\mathbf{1 5}$, is formed within $1 \mathrm{ps}$. This is in excellent agreement with our previous observation ${ }^{28,29}$ of the same nitrene in acetonitrile. This singlet nitrene, like all other singlet arylnitrenes, ${ }^{10}$ has an open-shell electronic structure. ${ }^{31,32}$ As ${ }^{\mathbf{1}} \mathbf{5}$ decays, a peak centered at $465 \mathrm{~nm}$ is formed, with an isosbestic point at $380 \mathrm{~nm}$. On the basis of McClelland's work, ${ }^{2,4}$ the newly formed $465 \mathrm{~nm}$ band is assigned to $p$-biphenylylnitrenium cation 6. This nitrenium ion has a closed-shell singlet ground state. ${ }^{33,34}$ The rate of formation of the $465 \mathrm{~nm}$ band is too slow to be determined accurately with our spectrometer, and our best estimation of this time constant is around $3 \mathrm{~ns}$. If the photolysis is performed in $88 \%$ formic acid, the decay rate of singlet $p$-biphenylylnitrene and the formation rate of its corresponding nitrenium cation are identical within experimental error, with a

(31) Kim, S. J.; Hamilton, T. P.; Schaefer, H. F., III. J. Am. Chem. Soc. 1992, $114,5349-5355$.

(32) Hrovat, D. A.; Waali, E. E.; Borden, W. T. J. Am. Chem. Soc. 1992, 114 $8698-8699$.

(33) Cramer, C. J.; Dulles, F. J.; Falvey, D. E. J. Am. Chem. Soc. 1994, 116, 9787-9788.

(34) Cramer, C. J.; Falvey, D. E. Tetrahedron Lett. 1997, 38, 1515-1518. time constant of 11.5 ps (Supporting Information, Figure S1). The singlet nitrene decay in $88 \%$ formic acid is on the time scale of vibrational cooling of the nitrene in acetonitrile. ${ }^{28,29}$ Thus, it is possible that it is the vibrationally excited, rather than the thermalized singlet nitrene, which undergoes protonation. In $88 \%$ formic acid, nitrenium cation 6 has a lifetime of $50 \mathrm{~ns}$.

McClelland et al. ruled out azide excited states as the precursors of the nitrenium cations based on the fact that the quantum yields of decomposition of the azides remain unchanged over a $20 \%$ to $90 \%$ acetonitrile-water mixture, in spite of a decrease in the yield of the nitrenium cations at higher acetonitrile concentration. ${ }^{4}$ Consequently, they assigned the singlet nitrene as the precursor of the nitrenium cations. The direct evidence provided in this work confirms that nitrenes are the precursors of nitrenium cations, as first proposed by the McClelland group. ${ }^{2,4}$

2.1.2. Matrix Isolation Spectroscopy and Calculations. The photochemistry of $p$-biphenylyl azide in a pure Ar matrix is very similar to that of parent phenyl azide: ${ }^{30,35}$ After initial 254 $\mathrm{nm}$ photolysis with a low-pressure Hg lamp, a broad band between 390 and $540 \mathrm{~nm}$ is formed, indicating the presence of the triplet nitrene 5 (green trace b in Figure 2). On subsequent photolysis at $\lambda>515 \mathrm{~nm}$, the nitrene undergoes ring expansion to form the corresponding azepine derivative (cf., Scheme 2). In all cases the IR spectra calculated for the presumed structures are in excellent agreement with the experimental IR spectra (Supporting Information, Figure S2).

Introduction of $30 \% \mathrm{HCl}$ in the Ar matrix profoundly changes the photochemistry. The nitrene and the resulting azepine spectra are no longer observed. Instead, a different, intense band centered at $460 \mathrm{~nm}$ rises under the same conditions of photolysis (red trace $\mathrm{c}$ in Figure 2). This newly formed band is assigned to $p$-biphenylylnitrenium cation $\mathbf{6}$, consistent with the work of McClelland's LFP studies ${ }^{4}$ and the transient spectra described above.

(35) Bally, T. In Reactive Intermediate Chemistry; Moss, R. A., Platz, M. S., Jones, M., Eds.; John Wiley \& Sons, Inc.: Hoboken, NJ, 2004; pp 797845 . 


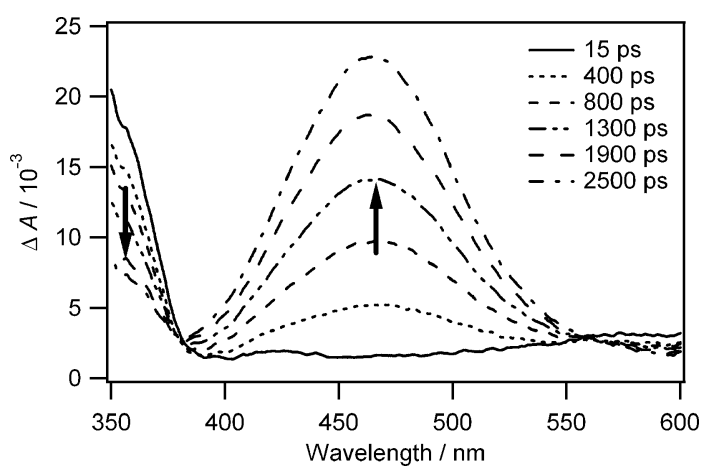

Figure 1. Transient spectra produced by ultrafast photolysis of $p$-biphenylyl azide 4 in acetonitrile-water (50\% vs 50\%) mixture. The spectra were generated by ultrafast LFP $(270 \mathrm{~nm})$ with a time window of $15-2500 \mathrm{ps}$.

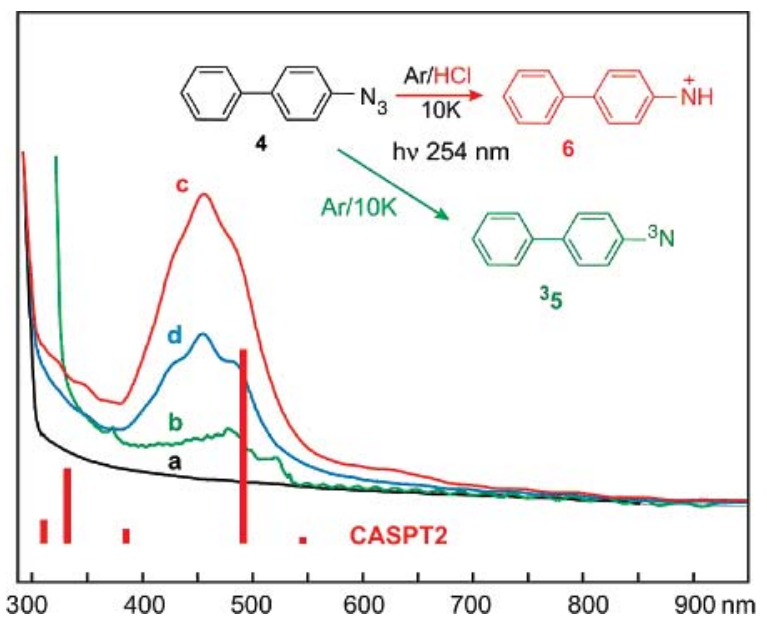

Figure 2. (a) UV-vis spectrum of $p$-biphenylyl azide $\mathbf{4}$ in an Ar matrix; (b) after photolysis at $254 \mathrm{~nm}$; (c) after photolysis at $254 \mathrm{~nm}$ in the presence of $30 \% \mathrm{HCl}$ in $\mathrm{Ar}$; (d) after bleaching at $\lambda>590 \mathrm{~nm}$.

Scheme 5

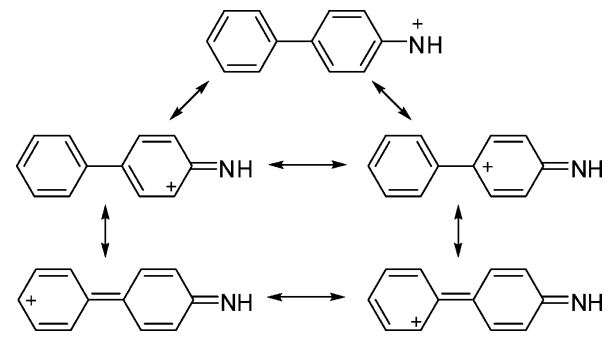

Calculations were performed to describe the nature of the electronic excitations responsible for the observed absorption. The geometry of the closed-shell singlet ground state of p-biphenylylnitrenium cation ${ }^{33,34}$ was optimized by B3LYP/6$31 G(d)$ (Supporting Information, Figure S3). The singlet-triplet gap of this ion was not calculated in this study, but analogous values have been reported by Cramer and co-workers. ${ }^{33,34}$ The two phenyl moieties were found to be twisted by $19.5^{\circ}$, in good agreement with the dihedral angle $17.6^{\circ}$ reported by Zhu et al. ${ }^{25}$ The presence of the $\mathrm{NH}^{+}$substituent changes the electronic structure of the molecule. In particular, the weight of the VB resonance structures which maintain a double bond between the two phenyl groups increases sensibly (Scheme 5 and Supporting Information, Figure S3) thus favoring planarization of the biphenylylnitrenium cation. However, the increased double-bond character between the two phenyl rings also leads to a shortening of the inter-ring distance by $0.045 \AA$, and the resulting additional
Table 1. Excited States and Oscillator Strength for $p$-Biphenylylnitrenium Cation 6 Calculated by the CASSCF and CASPT2 Methods

\begin{tabular}{|c|c|c|c|c|}
\hline CASSCF/eVa & CASPT2/eV $b$ & CASPT2/nm & $\begin{array}{l}\text { oscillator } \\
\text { strength }\end{array}$ & excitations $/ \%^{c}$ \\
\hline$(0.00)$ & $(0.00)$ & & & $74 \%$ ground config \\
\hline 2.42 & 2.28 & 545 & $1.2 \times 10^{-2}$ & $66 \%(\mathrm{H}-1 \rightarrow \mathrm{L})$ \\
\hline 3.60 & 2.52 & 493 & $5.4 \times 10^{-1}$ & $53 \%(\mathrm{H} \rightarrow \mathrm{L})$ \\
\hline 4.13 & 3.23 & 384 & $4.0 \times 10^{-2}$ & $\begin{array}{l}38 \%(\mathrm{H}-2 \rightarrow \mathrm{L}) \\
+25 \%(\mathrm{H}-2 \rightarrow \mathrm{L}+ \\
\quad \mathrm{H} \rightarrow \mathrm{L})\end{array}$ \\
\hline 4.97 & 3.75 & 330 & $2.1 \times 10^{-1}$ & highly mixed \\
\hline 5.06 & 4.16 & 298 & $1.2 \times 10^{-1}$ & highly mixed \\
\hline 5.41 & 3.93 & 315 & $6.6 \times 10^{-2}$ & highly mixed \\
\hline
\end{tabular}

${ }^{a}$ Active space comprises 10 electrons in $10 \pi$ orbitals, ground state energy: -514.557109 hartree. ${ }^{b}$ Ground state energy: -516.086437 hartree. ${ }^{c}$ Main excitations in the CASSCF wave function, where $\mathrm{H}=\mathrm{HOMO}$ and $\mathrm{L}=\mathrm{LUMO}$.

steric hindrance of the ortho hydrogen atoms means that planarity is not reached in $p$-biphenylylnitrenium cation, in spite of the stronger inter-ring double-bond character.

At the optimized geometry, the excited states were calculated by the CASPT2 method, based on a reference CASSCF wave function with an active space comprising 10 electrons in 10 orbitals. The orbitals which are involved mainly in the excitations that lead to the observed bands of $\mathbf{6}$ are listed in Table 1 and shown in Figure S4 of the Supporting Information. The first excitation, predicted at $545 \mathrm{~nm}$, corresponds mainly to HOMO $\rightarrow$ LUMO electron promotion but, owing to poor overlap between the ground state and the excited-state wave function, the transition moment is small. The following excitation, predicted at $493 \mathrm{~nm}$, is composed of a 53\% HOMO $\rightarrow$ LUMO excitation. The intensity of this band is higher because of greater overlap of the MOs between which the electronic promotion occurs. Higher excitations are predicted with a lower intensity, and all of them are of mixed character involving mainly excitations to the $\pi$-LUMO. As a result of the essentially nonbonding character of the LUMO, promoting electrons into higher virtual orbitals requires more energy than promoting them from lower occupied MOs to the LUMO.

The quantitative accord of the CASPT2 calculations (red bars in Figure 2) with experiment is satisfactory, and the main strong band, mainly due to HOMO $\rightarrow$ LUMO excitation, is well reproduced.

The corresponding IR spectra (Figure 3), recorded under the same conditions of photolysis as the UV-vis spectra in Figure 2 (red trace), show some peaks that increase after the first irradiation at $254 \mathrm{~nm}$ (spectrum b) and decrease on bleaching the photoproduct at $\lambda>590 \mathrm{~nm}$ (spectrum c). Dashed lines associate these bands with peaks in the calculated spectrum a of the $p$-biphenylylnitrenium cation. The position and relative intensity of most of the bands are reproduced reasonably well by the B3LYP calculations (spectrum a in Figure 3), but accord with experiment is somewhat lacking because some important calculated bands are missing in the experimental spectrum.

A possible origin of the poor matching may be the significant increase of the polarity of the medium containing the cation, caused by the presence of $\mathrm{HCl}$ in the matrix. Hence, interaction with the solvent, not considered in the calculations, could acquire significant importance in correctly describing the force field of the molecule. In particular, the resulting IR spectrum could have 


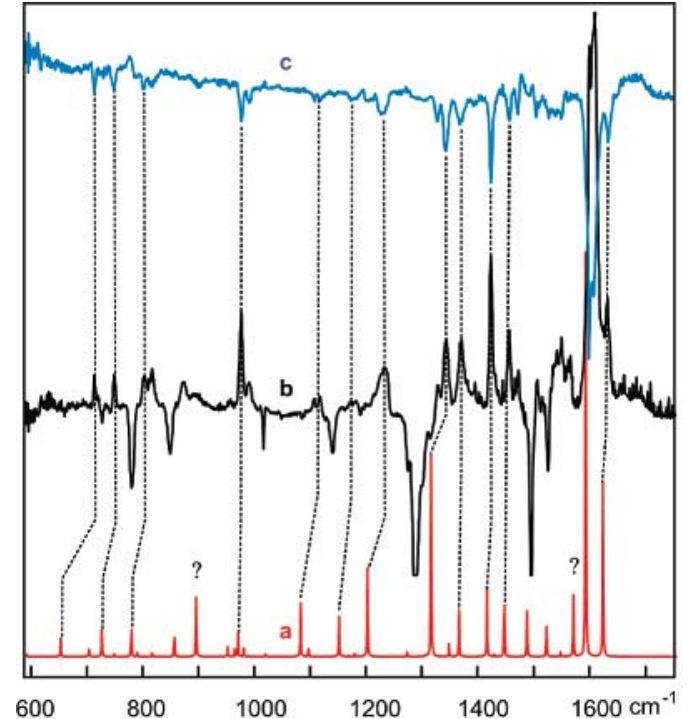

Figure 3. (a) IR spectrum of 6 calculated by B3LYP/6-31G*; (b) IR spectrum produced by bleaching of $p$-biphenylyl azide $4 \mathrm{in} \mathrm{Ar} / \mathrm{HCl}$ at 254 $\mathrm{nm}$ (negative peaks) and formation of the nitrenium cation $\mathbf{6}$ (positive peaks); (c) bleaching of 6 by irradiation at $\lambda>590 \mathrm{~nm}$ (negative peaks).

some shifts in the positions and in the intensities of some bands, while the general pattern could still be maintained.

The IR spectra do not reveal what happens upon bleaching of 6 , because no major bands rise in the process (blue trace c in Figure 3). A possibility is that on photoexcitation 6 reacts with the neighboring chloride anion, as was posited by McIlroy et al. in the case of the diphenylnitrenium cation, which was found to react with $\mathrm{Cl}^{-}$near the diffusion limit, ${ }^{36}$ or that it gives its proton back to $\mathrm{Cl}^{-}$.

\section{2. o-Biphenylylnitrenium Cation.}

2.2.1. Ultrafast Spectroscopy. In acetonitrile, the lifetime of singlet $o$-biphenylylnitrene $\mathbf{8}$ is only 16 ps, because $\mathbf{8}$ is deactivated by the extremely rapid formation of azirine 9 and isocarbazole 12 $\mathbf{1 2}^{28,29}$ (see Scheme 3). Hence, highly acidic conditions are necessary to produce the $o$-biphenylylnitrenium cation $\mathbf{1 1}$ in competition with the two intramolecular cyclizations.

Ultrafast photolysis (270 nm) of o-biphenylyl azide 7 in $88 \%$ formic acid produces the spectra in Figure 4. A transient absorption band centered at $400 \mathrm{~nm}$ is formed within $1 \mathrm{ps}$, which is assigned to singlet $o$-biphenylylnitrene $\mathbf{8}$, consistent with our previous observation ${ }^{28,29}$ of the same nitrene in acetonitrile. As singlet $o$-biphenylylnitrene decays, a peak centered at $610 \mathrm{~nm}$ is formed, with an isosbestic point at 465 $\mathrm{nm}$. By analogy with the prior example of $p$-biphenylyl azide, the carrier of the $610 \mathrm{~nm}$ band is assigned to $o$-biphenylylnitrenium cation 11 . The singlet nitrene decay in $88 \%$ formic acid is also on the time scale of vibrational cooling of the nitrenes in acetonitrile..$^{28,29}$ Once again it is the vibrationally excited, rather than the thermalized singlet nitrene, which undergoes protonation.

Global fitting of the decay at $400 \mathrm{~nm}$ and the growth at 610 $\mathrm{nm}$ gives a time constant of 7.7 ps (Supporting Information, Figure S5). In acetonitrile, the lifetime of singlet $o$-biphenylylnitrene is $16 \mathrm{ps}$, which is mainly deactivated by intramolecular cyclization to azirine 9 and isocarbazole 12. Assuming that

(36) McIlroy, S.; Moran, R. J.; Falvey, D. E. J. Phys. Chem. A 2000, 104, $11154-11158$.

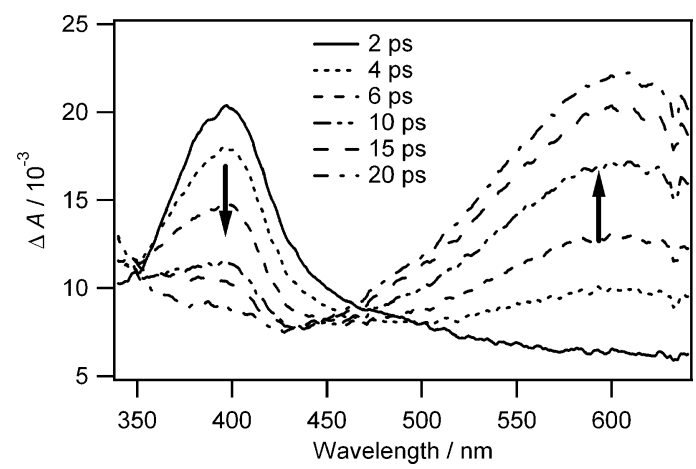

Figure 4. Transient spectra produced by ultrafast photolysis of $o$-biphenylyl azide 7 in $88 \%$ formic acid. The spectra were generated by ultrafast LFP $(270 \mathrm{~nm})$ with a time window of $2-20 \mathrm{ps}$.

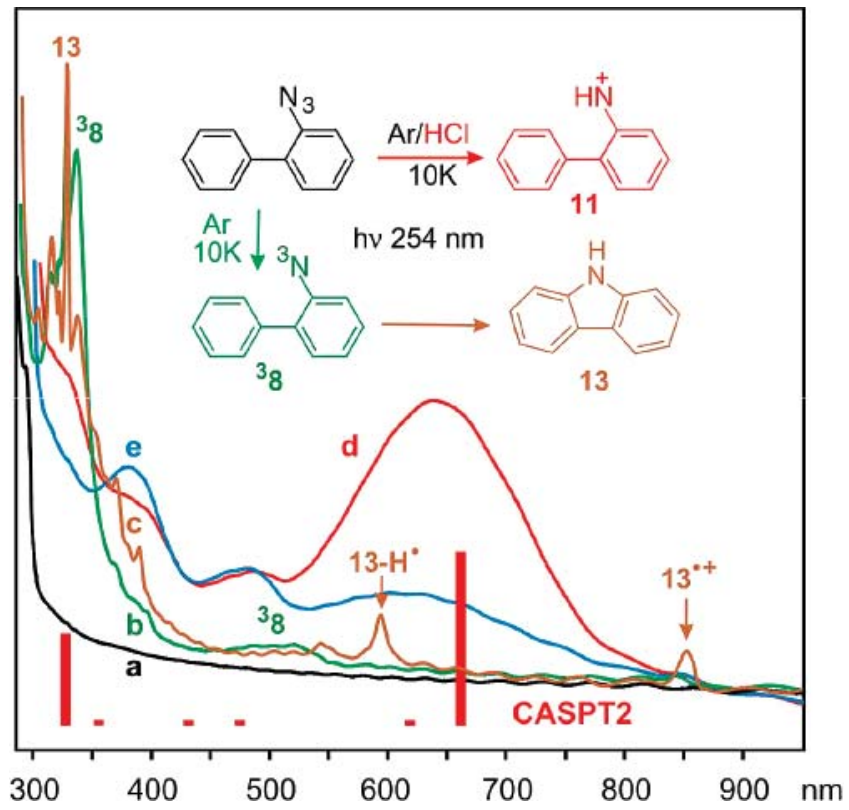

Figure 5. (a) UV-vis spectrum of o-biphenylyl azide 7 in Ar; (b) after short bleaching at $254 \mathrm{~nm}$; (c) after longer bleaching at $254 \mathrm{~nm}$; (d) after bleaching at $254 \mathrm{~nm}$ in the presence of $30 \% \mathrm{HCl}$ in $\mathrm{Ar}$; (e) after subsequent bleaching of $\mathbf{1 1}$ at $\lambda>590 \mathrm{~nm}$.

intramolecular decay processes of singlet $o$-biphenylylnitrene have the same rates in $88 \%$ formic acid as in acetonitrile, we deduce that the apparent protonation rate constant is $6.7 \times 10^{10}$ $\mathrm{s}^{-1}$ in $88 \%$ formic acid. Based on this assumption, we can also conclude that $52 \%$ of the singlet $o$-biphenylylnitrene is protonated in this acidic solvent. The carrier of the $610 \mathrm{~nm}$ band shows only very little decay in a 3 ns time window. Its lifetime of $27 \mathrm{~ns}$ in $88 \%$ formic acid was determined by ns time-resolved LFP techniques.

2.2.2. Matrix Isolation. In a pure $\mathrm{Ar}$ matrix the first photoproduct of $o$-biphenylyl azide, obtained by short UV photolysis, is the triplet nitrene with its intense peak at $340 \mathrm{~nm}$ and the broad band at $450-550 \mathrm{~nm}$ (green trace $\mathrm{b}$ in Figure 5). ${ }^{37}$ This species is extremely photosensitive: on continuing the same irradiation for a few more minutes, the nitrene attacks the adjacent ring to eventually form carbazole $\mathbf{1 3}$, which can be readily identified by its group of sharp bands at 300-350 $\mathrm{nm}$ (brown trace $\mathrm{c}$ in Figure 5). ${ }^{38}$

(37) Tsao, M.-L.; Gritsan, N.; James, T. R.; Platz, M. S.; Hrovat, D. A.; Borden, W. T. J. Am. Chem. Soc. 2003, 125, 9343-9358.

(38) Reiser, A.; Willets, F. W.; Terry, G. C.; Williams, V.; Marley, R. Trans. Faraday Soc. 1968, 64, 3265-3275. 
Table 2. Excited States and Oscillator Strengths for o-Biphenylylnitrenium Cation 11 Calculated by the CASSCF and CASPT2 Methods

\begin{tabular}{|c|c|c|c|c|}
\hline CASSCF/eVa & CASPT2/eV & CASPT2/nm & $\begin{array}{l}\text { oscillator } \\
\text { strength }\end{array}$ & excitations $/ \%^{c}$ \\
\hline$(0.00)$ & $(0.00)$ & & & $79 \%$ ground config \\
\hline 2.51 & 1.18 & 658 & $3.6 \times 10^{-1}$ & $64 \%(\mathrm{H} \rightarrow \mathrm{L})$ \\
\hline 2.79 & 2.01 & 615 & $8.5 \times 10^{-3}$ & $\begin{array}{c}32 \%(\mathrm{H}-4 \rightarrow \mathrm{L})+ \\
29 \%(\mathrm{H}-1 \rightarrow \mathrm{L})\end{array}$ \\
\hline 3.31 & 2.54 & 489 & $6.9 \times 10^{-3}$ & highly mixed \\
\hline 4.09 & 2.86 & 433 & $5.0 \times 10^{-3}$ & highly mixed \\
\hline 4.59 & 3.50 & 354 & $8.4 \times 10^{-3}$ & highly mixed \\
\hline 4.77 & 3.83 & 324 & $1.9 \times 10^{-1}$ & highly mixed \\
\hline
\end{tabular}

${ }^{a}$ Active space comprises 10 electrons in $10 \pi$ orbitals, ground state energy: -514.541996 hartree. ${ }^{b}$ Ground state energy: -516.080167 hartree. ${ }^{c}$ Main excitation in the CASSCF wave function, where $\mathrm{H}=\mathrm{HOMO}$ and $\mathrm{L}=\mathrm{LUMO}$.

In addition, the spectrum reveals the presence of the carbazolyl radical $\mathbf{1 3}-\mathrm{H}^{\bullet}$ (sharp band at $600 \mathrm{~nm}$ ), and even of the radical cation of carbazole, $\mathbf{1 3}^{+\bullet}$ (sharp band at $850 \mathrm{~nm}$ ) ${ }^{39} \mathrm{It}$ is known that aromatic amines can undergo ionization on UV irradiation. ${ }^{39,40}$

The corresponding IR spectra (Supporting Information, Figure S6) demonstrate that the formation of carbazole is indeed the dominant process. However, some small bands which increase during the first photolysis and decrease after the second photolysis, dashed lines, appear to be due to the presence of the nitrene, whose calculated spectrum matches reasonably well with experiment. In addition, a band in the region of $1900 \mathrm{~cm}^{-1}$ is also present and increases in both photolyses. The only species which can have this kind of vibrational spectrum is the keteneimine $\mathbf{1 0}$ derived from a ring expansion process (see Scheme 3). No IR evidence was found for the carbazolyl radical or the radical cation, which seem to be formed only in small quantities.

The reactivity of the azide completely changes upon introducing 30\% $\mathrm{HCl}$ into the matrix (red trace d in Figure 5). Under the same conditions of photolysis, a different and much more intense band rises between 550 and $750 \mathrm{~nm}$, which is assigned to o-biphenylylnitrenium cation $\mathbf{1 1}$ based on the transient spectra in Figure 4. Again the nitrenium cation can be bleached by subsequent photolysis at $\lambda>600 \mathrm{~nm}$ (blue trace $\mathrm{e}$ in Figure 5).

Again quantum chemical calculations were performed in order to describe the absorptions associated with the nitrenium cation 11. In the B $3 L Y P / 6-31 G(d)$ geometry (Supporting Information, Figure S7) the two phenyl moieties are found to be twisted by $28.8^{\circ}$, nearly $50 \%$ more than in the $p$-biphenylylnitrenium cation, due to the increase of the steric hindrance introduced by the ortho $\mathrm{NH}^{+}$substituent. In spite of this, the resonance structures with an inter-ring double bond seem more predominant because that bond is slightly shorter (1.435 $\AA$ compared to $1.441 \AA$ of the para isomer, Supporting Information, Figure S3).

At this geometry, CASPT2 calculations were performed to predict the positions and intensities of the absorption bands of the nitrenium cation (Table 2 and bars on the bottom of Figure 5). The strong visible transition, predicted at $654 \mathrm{~nm}$, in striking

(39) Brede, O.; Maroz, A.; Hermann, R.; Naumov, S. J. Phys. Chem. A 2005 , 109, 8081-8087

(40) Hiyoshi, R.; Hiura, H.; Sakamoto, Y.; Mizuno, M.; Sakai, M.; Takahashi, H. J. Mol. Struct. 2003, 661-662, 481-489.

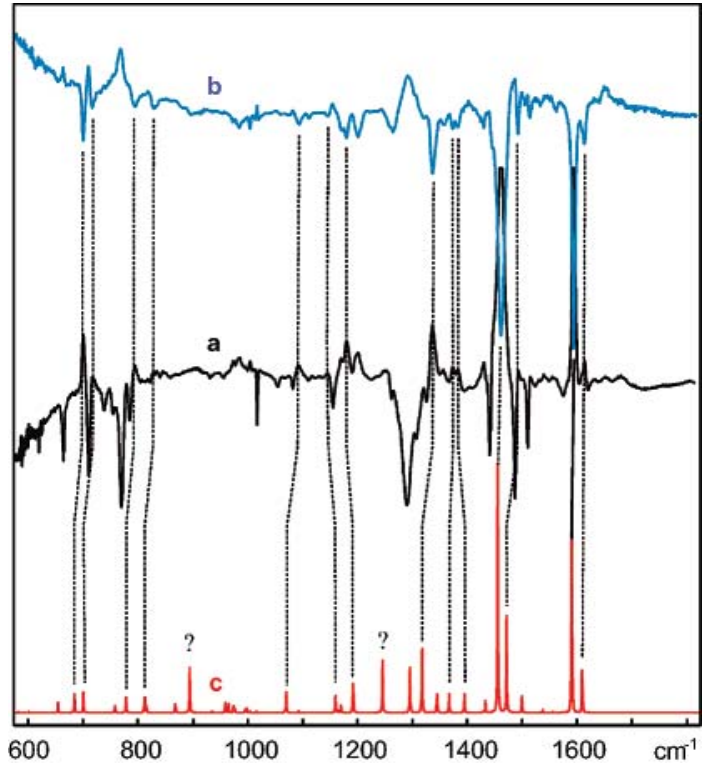

Figure 6. (a) IR spectrum produced by bleaching of $o$-biphenylyl azide in $\mathrm{Ar} / \mathrm{HCl}$ at $254 \mathrm{~nm}$ (negative peaks) and formation of the nitrenium cation 11 (positive peaks); (b) bleaching of 11 (negative peaks) by irradiation at $\lambda>590 \mathrm{~nm}$; (c) IR spectrum of 11 calculated by B3LYP/6$31 \mathrm{G}^{*}$.

accord with experiment, is again predominantly due to HOMO $\rightarrow$ LUMO electron promotion. The following weak transition, predicted at $615 \mathrm{~nm}$, has an oscillator strength that is more than 10 times smaller, and the CASSCF wave function of the corresponding excited state is mainly composed of $29 \%$ HOMO- $1 \rightarrow$ LUMO and 32\% HOMO-4 $\rightarrow$ LUMO excitation. Thus, the order of the first two excited states is inverted on going from $p$ - to $o$-biphenylylnitrenium cation. All the other excited states in the calculated range are highly mixed, as in the $p$-biphenylylnitrenium cation. The major electron promotions occur again to the LUMO, which, because of its essentially nonbonding character, lies at very low energy (Supporting Information, Figure S8).

The corresponding IR spectra (Figure 6) reveal how bands of the supposed nitrenium cation initially generated (spectrum a) and subsequently destroyed (spectrum b) are in good agreement with those of the simulated spectrum (spectrum c), calculated by the DFT method, although some of the weaker calculated bands again seem to be missing from the experimental spectra (cf., discussion on the spectra shown in Figure 3). In this case it seems that on bleaching of the nitrenium cation, the nitrene is reformed by deprotonation, although the evidence for this, admittedly, is not overwhelming.

\subsection{1-Naphthylnitrenium Cation.}

2.3.1. Ultrafast Spectroscopy. Ultrafast photolysis $\left(\lambda_{\mathrm{ex}}=\right.$ $270 \mathrm{~nm}$ ) of 1-naphthyl azide $\mathbf{1 4}$ (Scheme 4) in 88\% formic acid produces the spectra shown in Figure 7. A peak centered at $380 \mathrm{~nm}$ is formed within $1 \mathrm{ps}$ of the laser pulse. The carrier of this absorption is assigned to singlet 1-naphthylnitrene $\mathbf{1 5}$, consistent with its previous observation ${ }^{29}$ in acetonitrile. As singlet 1-naphthylnitrene decays, a new species is formed, with an absorption centered at $495 \mathrm{~nm}$ and an isosbestic point at $430 \mathrm{~nm}$. The carrier of the $495 \mathrm{~nm}$ absorption band is assigned to 1-naphthylnitrenium cation 17. This is consistent with Kung and Falvey's report of the spectrum of the closely related species $N$-methyl- $N$-1-naphthylnitrenium cation. ${ }^{16}$ This assignment is 


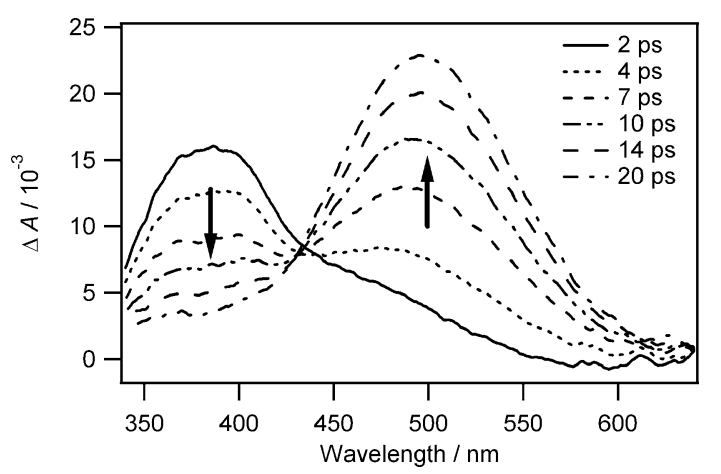

Figure 7. Transient spectra produced by ultrafast photolysis of 1-naphthyl azide 14 in $88 \%$ formic acid. The spectra were generated by ultrafast LFP $(270 \mathrm{~nm})$ with a time window of $2-20 \mathrm{ps}$.

Table 3. Excited States and Transition Strengths for 1-Naphthylnitrenium Cation 17 Calculated by the CASSCF and CASPT2 Methods

\begin{tabular}{cccll}
\hline CASSCF/eV $^{a}$ & CASPT2/eV $^{b}$ & CASPT2/nm & $\begin{array}{c}\text { oscillator } \\
\text { strength }\end{array}$ & \multicolumn{1}{c}{ excitations $/ \%^{c}$} \\
\hline$(0.0)$ & $(0.00)$ & & & $69 \%$ ground config \\
2.48 & 2.32 & 535 & $9.7 \times 10^{-4}$ & $54 \%(\mathrm{H}-1 \rightarrow \mathrm{L})$ \\
2.99 & 2.36 & 526 & $4.3 \times 10^{-3}$ & $55 \%(\mathrm{H} \rightarrow \mathrm{L})$ \\
4.36 & 3.90 & 318 & $1.7 \times 10^{-3}$ & $21 \%(\mathrm{H}-2 \rightarrow \mathrm{L})$ \\
& & & & $+16 \%(2 * \mathrm{H} \rightarrow \mathrm{L})$ \\
& & & & $+13 \%(\mathrm{H}-3 \rightarrow \mathrm{L})$ \\
4.59 & 4.05 & 306 & $1.8 \times 10^{-3}$ & highly mixed \\
5.24 & 4.77 & 260 & $2.9 \times 10^{-3}$ & highly mixed \\
5.60 & 4.44 & 279 & $6.1 \times 10^{-3}$ & highly mixed \\
\hline
\end{tabular}

${ }^{a}$ Active space comprises 10 electrons in $10 \pi$ orbitals, ground state energy: -437.670042 hartree. ${ }^{b}$ Ground state energy: -438.931647 hartree. ${ }^{c}$ Main excitation in the CASSCF wave function, where $\mathrm{H}=\mathrm{HOMO}$ and $\mathrm{L}=$ LUMO.

also consistent with CASPT2 calculations (Table 3). Thus, there is little doubt that this assignment is correct.

Global fitting of the decay at $380 \mathrm{~nm}$ and the growth at 495 $\mathrm{nm}$ gives a time constant of 8.4 ps (Supporting Information, Figure S9). In acetonitrile, the lifetime of singlet 1-naphthylnitrene (12 ps) is mainly limited by intramolecular cyclization to azirine 16 (Scheme 4). If we make the same assumption as in the case of $o$-biphenylyl azide, assuming the formation of azirine has the same rate in $88 \%$ formic acid as in acetonitrile, the apparent protonation rate constant is $3.6 \times 10^{10} \mathrm{~s}^{-1}$ in $88 \%$ formic acid. Therefore, we can also conclude that $30 \%$ of the singlet 1-naphthylnitrene is protonated in this solvent. As before, it is the vibrationally excited, rather than the thermalized singlet nitrene, which undergoes protonation. The lifetime of 1-naphthylnitrenium cation is only 860 ps (Supporting Information, Figure S10), which explains why this species cannot be observed by nanosecond time-resolved LFP methods.

2.3.2. Matrix Isolation. The photolysis of 1-naphthyl azide in a pure Ar matrix was first studied by Dunkin and Thomson, ${ }^{41}$ who conjectured that the initially formed 1-naphthylnitrene produces azirine $\mathbf{1 6}$ and that the azirine can be subsequently converted to the keteneimine by further irradiation. Reiser et al. ${ }^{42}$ irradiated the azide in an organic glassy matrix at $77 \mathrm{~K}$ and recorded the optical spectra of the products. They reported absorption bands at 223, 367, and $536 \mathrm{~nm}$ that they attributed

(41) Dunkin, I. R.; Thomson, P. C. P. J. Chem. Soc., Chem. Commun. 1980, 499-501.

(42) Reiser, A.; Bowes, G.; Horne, R. J. Trans. Faraday Soc. 1966, 62, $3162-$ 3169 .

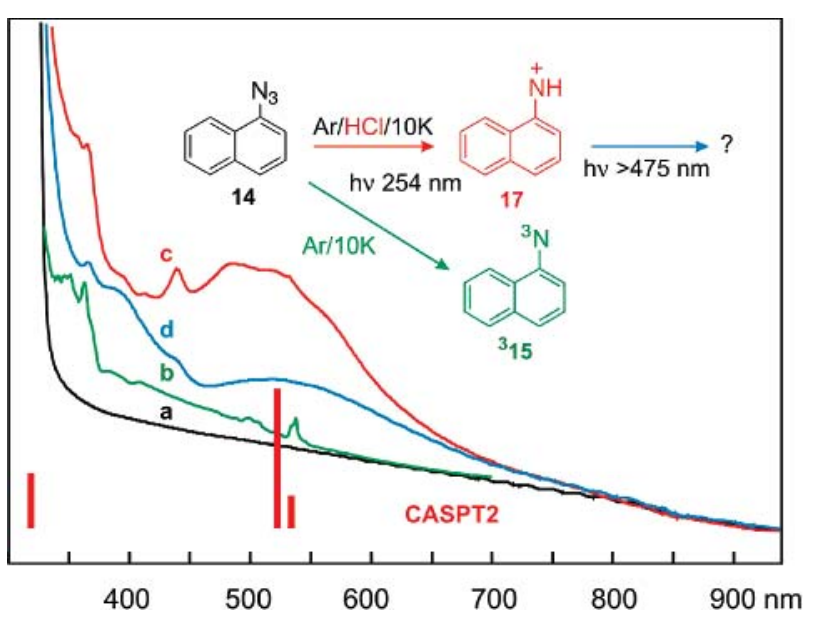

Figure 8. (a) UV-vis spectrum of 1-napththyl azide 14 in $\mathrm{Ar}$; (b) after bleaching at $254 \mathrm{~nm}$; (c) after bleaching at $254 \mathrm{~nm}$ in the presence of $30 \% \mathrm{HCl}$ in $\mathrm{Ar}$; (d) after subsequent bleaching of $\mathbf{1 7}$ at $\lambda>$ $475 \mathrm{~nm}$.

to the corresponding nitrene. Schrock and Schuster performed nanosecond time-resolved LFP of 1-naphthyl azide in benzene, obtaining direct evidence by transient spectroscopy of the corresponding triplet nitrene, which eventually forms $1,1^{\prime}$ azonaphthalene. ${ }^{43}$ Recently, Maltsev et al. ${ }^{44}$ reported a more extensive matrix UV-vis and IR study of the photochemistry of 1-naphthyl azide in argon, and the singlet surface of 1-naphthylnitrene was studied by modern computational techniques. Tsao and Platz used LFP with IR detection to directly observe the benzazirine intermediate. ${ }^{45}$ Its lifetime $(2.3 \mu \mathrm{s})$ was in excellent agreement with the value deduced by Schrock and Schuster. ${ }^{43}$

In our experiment, after a first irradiation of 1-naphthyl azide at $254 \mathrm{~nm}$ the previously reported spectrum of ${ }^{\mathbf{3}} \mathbf{1 5}$ is observed (green trace b in Figure 8, sharp $540 \mathrm{~nm}$ band). Further photolysis leads initially to azirine $\mathbf{1 6}$, which opens to sevenmembered ring products, as described in detail in ref 25 .

In a matrix containing $30 \% \mathrm{HCl}$, the spectrum obtained after initial UV photolysis with a low-pressure $\mathrm{Hg}$ lamp has a completely different shape characterized by an intense broad absorption in the region between 400 and $650 \mathrm{~nm}$ (red trace c in Figure 8 ). The band can be bleached by irradiation at $\lambda>$ $475 \mathrm{~nm}$ (blue trace $\mathrm{d}$ in Figure 8). The electronic excitations of the 1-naphthylnitrenium cation predicted by a CASPT2 calculation (red bars in Figure 8 and Table 3), and the transient spectra shown in Figure 7, secure the assignment of the $500 \mathrm{~nm}$ band to the nitrenium cation. As mentioned earlier, Kung and Falvey ${ }^{16}$ reported the solution-phase spectrum of the closely related species, $N$-methyl- $N$-1-naphthylnitrenium cation with a broad band centered at $500 \mathrm{~nm}$. This is further evidence that we have succeeded in forming and detecting 1-naphthylnitrenium cation.

For this molecule, the first excitation is characterized by HOMO- $\rightarrow$ LUMO electronic promotion. In the second excited state the $\mathrm{HOMO} \rightarrow$ LUMO electronic transition contributes with a weight of $55 \%$ to the CASSCF wave function (Table 3 ). Despite the change from a biphenylyl to a naphthyl group, the

(43) Schrock, A. K.; Schuster, G. B. J. Am. Chem. Soc. 1984, 106, 5234-5240.

(44) Maltsev, A.; Bally, T.; Tsao, M.-L.; Platz, M. S.; Kuhn, A.; Vosswinkel, M.; Wentrup, C. J. Am. Chem. Soc. 2004, 126, 237-249.

(45) Tsao, M.-L.; Platz, M. S. J. Phys. Chem. A 2004, 108, 1169-1176. 


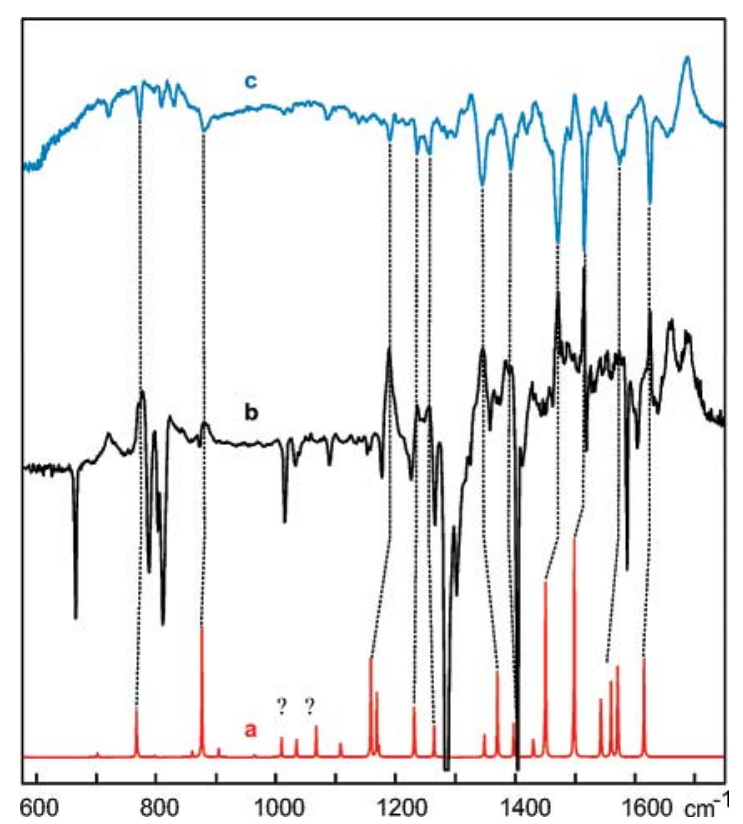

Figure 9. (a) IR spectrum of $\mathbf{1 7}$ calculated by B3LYP/6-31G*; (b) IR spectrum produced by bleaching of 1-naphthyl azide 14 in $\mathrm{Ar} / \mathrm{HCl}$ at $254 \mathrm{~nm}$ (negative peaks) and formation of the nitrenium cation $\mathbf{1 7}$ (positive peaks); (c) bleaching of $\mathbf{1 7}$ (negative peaks) by irradiation at $\lambda>$ $475 \mathrm{~nm}$.

LUMO maintains an essentially nonbonding character, favoring excitations from filled orbitals to the LUMO (Supporting Information, Figure S11).

In Figure 9, the calculated IR spectrum of 1-naphthylnitrenium cation (spectrum a) is correlated with a series of bands which are generated by the initial photolysis at $254 \mathrm{~nm}$ of $\mathbf{1 4}$ in an Ar matrix containing $30 \% \mathrm{HCl}$ (spectrum b) and bleached by the second irradiation $(\lambda>475 \mathrm{~nm}$, spectrum $\mathrm{c})$. The agreement with experiment (dashed lines in Figure 9) is satisfactory and seems to leave little doubt about the identity of the species obtained. However, the identity of the species formed upon bleaching is again not revealed by the IR spectrum which shows interesting unassigned bands at 1600$1700 \mathrm{~cm}^{-1}$.

Nevertheless we note some disagreement between the experimental spectra, in particular in the case of the naphthylnitrenium cation 17 where some major experimental bands, e.g., the pair between 1620 and $1700 \mathrm{~cm}^{-1}$, are not predicted to occur. We believe that this may be due to (a) photoprotonation of $\mathbf{1 5}$ at the aromatic ring, rather than at the $\mathrm{N}$-atom, or (b) attachment of the chloride anion to the aromatic ring, as was found to occur in nitrenium cations obtained by photolysis of aminopyridinium cations. ${ }^{24} \mathrm{We}$ are currently exploring these possibilities.

\section{Experimental Section}

3.1. Synthesis. The syntheses of the azides used in this work have been previously reported. ${ }^{1-4,37,45}$

3.2. Matrix Isolation Spectroscopy. ${ }^{35}$ A few ground crystals of azides were placed in a U-tube attached to the inlet system of a closedcycle cryostat. A mixture of argon (Carbagas, 99.995\%) with 10\% nitrogen (Carbagas, 99.995\%) was flowed through the U-tube and slowly deposited on a CsI window (UV transparent quality, Korth Kristalle $\mathrm{GmbH}$ ) maintained at ca. $20 \mathrm{~K}$. In the protonation experiments, $30 \%$ dry gaseous $\mathrm{HCl}$ was added to the mixture. During deposition the temperature of the U-tube was kept at $14{ }^{\circ} \mathrm{C}$ for $p$-biphenylyl azide, $19{ }^{\circ} \mathrm{C}$ for $o$-biphenylyl azide, and $-27{ }^{\circ} \mathrm{C}$ for 1-naphthyl azide. Photolysis of the azides was performed with a low-pressure Hg lamp, whereas for the bleaching of the nitrenium cations a high-pressure $\mathrm{Hg} / \mathrm{Xe}$ arc was used with $590 \mathrm{~nm}$ or $475 \mathrm{~nm}$ cutoff filters (cf., captions of figures). Electronic absorption spectra were recorded on a Perkin-Elmer Lambda 900 spectrometer (200-1000 nm). IR spectra were measured on a Bomem DA3 interferometer $\left(4000-500 \mathrm{~cm}^{-1}\right)$ with a mercury cadmium telluride (MCT) detector.

3.3. Computational Chemistry. The geometries and harmonic vibrational frequencies of the three nitrenium cations $(\mathbf{6}, \mathbf{1 1}$, and 17) were calculated by the B3LYP density functional method ${ }^{46,47}$ using the $6-31 \mathrm{G}(\mathrm{d})$ basis set, with the Gaussian 03 suite of programs. ${ }^{48}$ All equilibrium structures were ascertained to be minima on the potential energy surfaces. The harmonic frequencies were scaled by a factor of 0.96 for their use in assigning the experimental IR spectra. ${ }^{49}$

Excited-state energies of the nitrenium cations were calculated at the above geometries by the CASSCF/CASPT2 procedure $^{50,51}$ with the ANO-S basis set of Pierloot et al..$^{52}$ using the MOLCAS program. ${ }^{53}$ In order to arrive at a satisfactory description of all excited states at the CASPT2 level (i.e., remove intruder states) it was necessary to resort to the level-shifting technique, ${ }^{54}$ whereby it was carefully ascertained that no artifacts are introduced.

3.4. Ultrafast Spectroscopy. Details of the ultrafast time-resolved spectrometer in use at The Ohio State University Center for Chemical and Biophysical Dynamics have been reported elsewhere. ${ }^{29}$

\section{Conclusions}

The lifetimes of certain singlet arylnitrenes at ambient temperature are too short to allow for their protonation to form the corresponding nitrenium cations on the nanosecond time scale. We have shown using ultrafast time-resolved flash photolysis methods that two such nitrenium cations can be conveniently generated from $p$ - and $o$-biphenylyl and 1-naphthyl azides in $88 \%$ formic acid. In this solvent, $o$-biphenylyl ( $\tau=$ $7.7 \mathrm{ps})$ and 1-naphthylnitrene ( $\tau=8.4 \mathrm{ps})$ are protonated and converted to nitrenium cations. In many respects, $88 \%$ aqueous formic acid is the ideal solvent for direct detection of monosubstituted arylnitrenium cations. The azide precursors dissolve readily and have sufficient stability in this solvent for photochemical studies, and the corresponding nitrenes are readily protonated, and the resultant nitrenium ions have relatively long lifetimes in this solvent. These experiments show also that the singlet nitrenes, rather than the excited states of the azides, are the direct precursors of the nitrenium cations as first proposed by McClelland et al. ${ }^{4}$ These same nitrenes can be protonated in argon/ $\mathrm{HCl}$ matrices to form persistent nitrenium cations which can be characterized by both electronic and vibrational spectroscopy and whose spectra are in excellent agreement with the predictions of theory. These two approaches

(46) Lee, C.; Yang, W.; Parr, R. G. Phys. Rev. B: Condens. Matter 1988, 37, $785-789$.

(47) Becke, A. D. J. Chem. Phys. 1993, 98, 5648-5652.

(48) Frisch, M. J.; et al. Gaussian 03, revision C.01; Gaussian, Inc.: Wallingford, CT, 2005.

(49) Scott, A. P.; Radom, L. J. Phys. Chem. 1996, 100, 16502-16513

(50) Roos, B. Adv. Chem. Phys. 1987, 69, 399-445.

(51) Andersson, K.; Roos, B. O. In Advanced Series in Physical Chemistry; 1995; Vol. 2, pp 55-109.

(52) Pierloot, K.; Dumez, B.; Widmark, P.-O.; Roos, B. O. Theor. Chim. Acta $1995,90,87-114$.

(53) Andersson, K.; Blomberg, M. R. A.; Fülscher, M. P.; Kellö, V.; Lindh, R.; Malmqvist, P.-A.; Noga, J.; Olson, J.; Roos, B. O.; Sadlej, A.; Siegbahn, P. E. M.; Urban, M.; Widmark, P.-O. MOLCAS, version 5. University of Lund, 2002.

(54) Roos, B. O.; Andersson, K.; Fuelscher, M. P.; Serrano-Andres, L.; Pierloot, K.; Merchan, M.; Molina, V. THEOCHEM 1996, 388, 257-276. 
expand the range of monoarylnitrenium cations which can be formed by protonation of singlet arylnitrenes.

Acknowledgment. Support of this work in Columbus by the National Science Foundation and the Ohio Supercomputer Center and in Fribourg by the Swiss National Science Foundation (Project No. 200020-113268) is gratefully acknowledged. G.B. is a holder of a "Homing" Grant from the Foundation for Polish Science (FNP) in the year 2007.
J.W. thanks the Ohio State University Graduate School for a Presidential Fellowship. 


\title{
SUPPORTING INFORMATION
}

\section{Ultrafast Spectroscopic and Matrix Isolation Studies of Para- and Ortho-Biphenylyl and 1-Naphthylnitrenium}

\section{Cations}

\author{
Jin Wang, ${ }^{a}$ Gotard Burdzinski, ${ }^{b}$ Zhendong Zhu, ${ }^{a}$ Matthew S. Platz, ${ }^{a}$ * \\ Claudio Carra ${ }^{c}$ and Thomas Bally ${ }^{c *}$
}

a Department of Chemistry, The Ohio State University, 100 West 18"th Avenue, Columbus, Ohio, 43210. ${ }^{\mathrm{b}}$ Quantum Electronics Laboratory, Faculty of Physics, Adam Mickiewicz University, 85 Umultowska, Poznan 61-614, Poland. ${ }^{c}$ Departement de Chimie, Universite de Fribourg, Chemin du Musée 9, CH-1700 Fribourg, Switzerland.

Version of April 16, 2007

Full quotation of the Gaussian Program (Reference 48)

M. J. Frisch, G. W. Trucks, H. B. Schlegel, G. E. Scuseria, M. A. Robb, J. R. Cheeseman, J. A. Montgomery, Jr., T. Vreven, K. N. Kudin, J. C. Burant, J. M. Millam, S. S. Iyengar, J. Tomasi, V. Barone, B. Mennucci, M. Cossi, G. Scalmani, N. Rega, G. A. Petersson, H. Nakatsuji, M. Hada, M. Ehara, K. Toyota, R. Fukuda, J. Hasegawa, M. Ishida, T. Nakajima, Y. Honda, O. Kitao, H. Nakai, M. Klene, X. Li, J. E. Knox, H. P. Hratchian, J. B. Cross, C. Adamo, J. Jaramillo, R. Gomperts, R. E. Stratmann, O. Yazyev, A. J. Austin, R. Cammi, C. Pomelli, J. W. Ochterski, P. Y. Ayala, K. Morokuma, G. A. Voth, P. Salvador, J. J. Dannenberg, V. G. Zakrzewski, S. Dapprich, A. D. Daniels, M. C. Strain, O. Farkas, D. K. Malick, A. D. Rabuck, K. Raghavachari, J. B. Foresman, J. V. Ortiz, Q. Cui, A. G. Baboul, S. Clifford, J. Cioslowski, B. B. Stefanov, G. Liu, A. Liashenko, P. Piskorz, I. Komaromi, R. L. Martin, D. J. Fox, T. Keith, M. A. Al-Laham, C. Y. Peng, A. Nanayakkara, M. Challacombe, P. M. W. Gill, B. Johnson, W. Chen, M. W. Wong, C. Gonzalez, and J. A. Pople, Gaussian 03, Rev. C-01, Gaussian, Inc., Wallingford CT, 2005. 


\section{List of Figures}

Figure S1. Ultrafast LFP (270 nm) of p-biphenylyl azide (probed at $350 \mathrm{~nm}$ and $465 \mathrm{~nm}) \ldots \ldots \ldots \ldots \ldots \ldots . . . . . . . . .33$

Figure S2. Difference IR spectra for the photolysis of p-biphenylyl azide ......................................S3

Figure S3. Geometry parameters for p-biphenylylnitrenium cation.............................................S4

Figure S4. Molecular orbitals of p-biphenylylnitrenium cation ...................................................S4

Figure S5. Ultrafast LFP $(270 \mathrm{~nm})$ of o-biphenylyl azide (probed at $400 \mathrm{~nm}$ and $610 \mathrm{~nm}) \ldots \ldots \ldots \ldots \ldots \ldots . . . . . . . .55$

Figure S6. Difference IR spectra for the photolysis of o-biphenylyl azide .......................................S5

Figure S7. Geometry parameters for o-biphenylylnitrenium cation...............................................S6

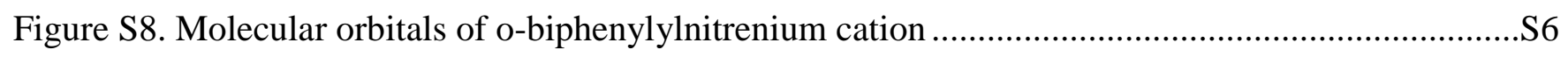

Figure S9. Ultrafast LFP $(270 \mathrm{~nm})$ of 1-naphthyl azide (probed at $380 \mathrm{~nm}$ and $495 \mathrm{~nm}) \ldots \ldots \ldots \ldots \ldots \ldots \ldots . . . .57$

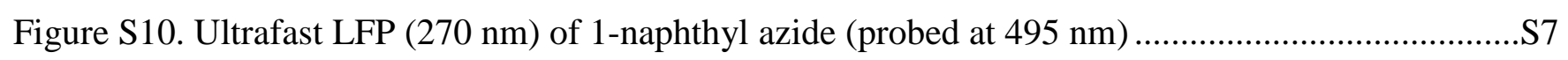

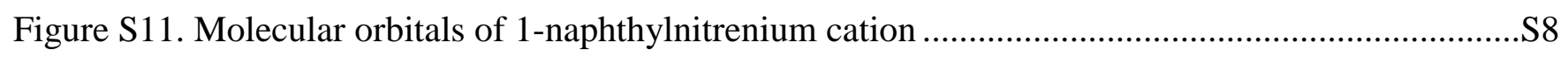

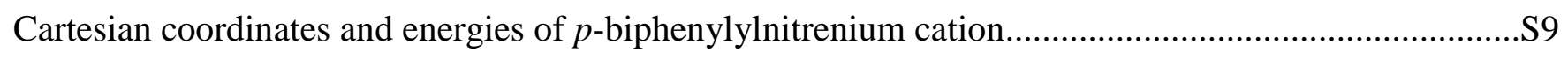

Cartesian coordinates and energies of $o$-biphenylylnitrenium cation..........................................S10

Cartesian coordinates and energies of 1 -naphthylnitrenium cation .............................................S11 


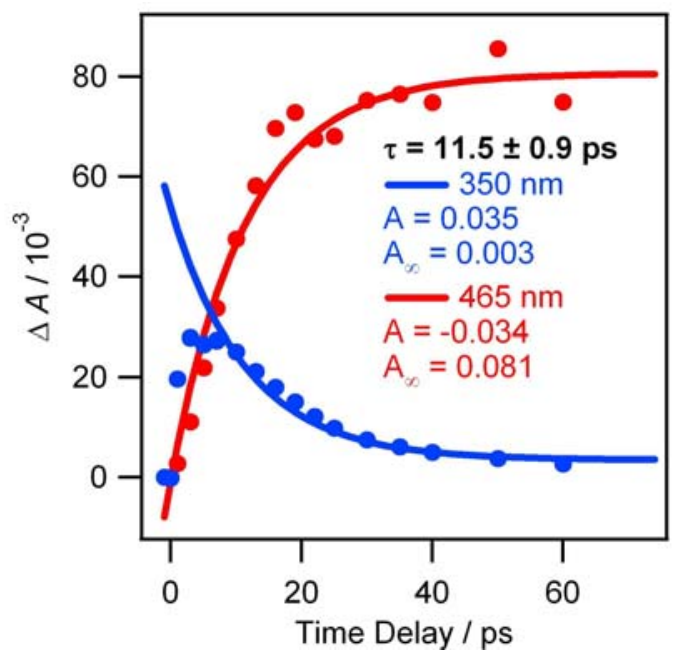

Figure S1. Kinetic traces of $p$-biphenylylnitrene (blue) and $p$-biphenylylnitrenium cation (red) in $88 \%$ formic acid; excited by ultrafast LFP at $270 \mathrm{~nm}$ and probed at $350 \mathrm{~nm}$ and $465 \mathrm{~nm}$, respectively. The two kinetic traces were globally fitted to mono-exponential functions with the same time constant.

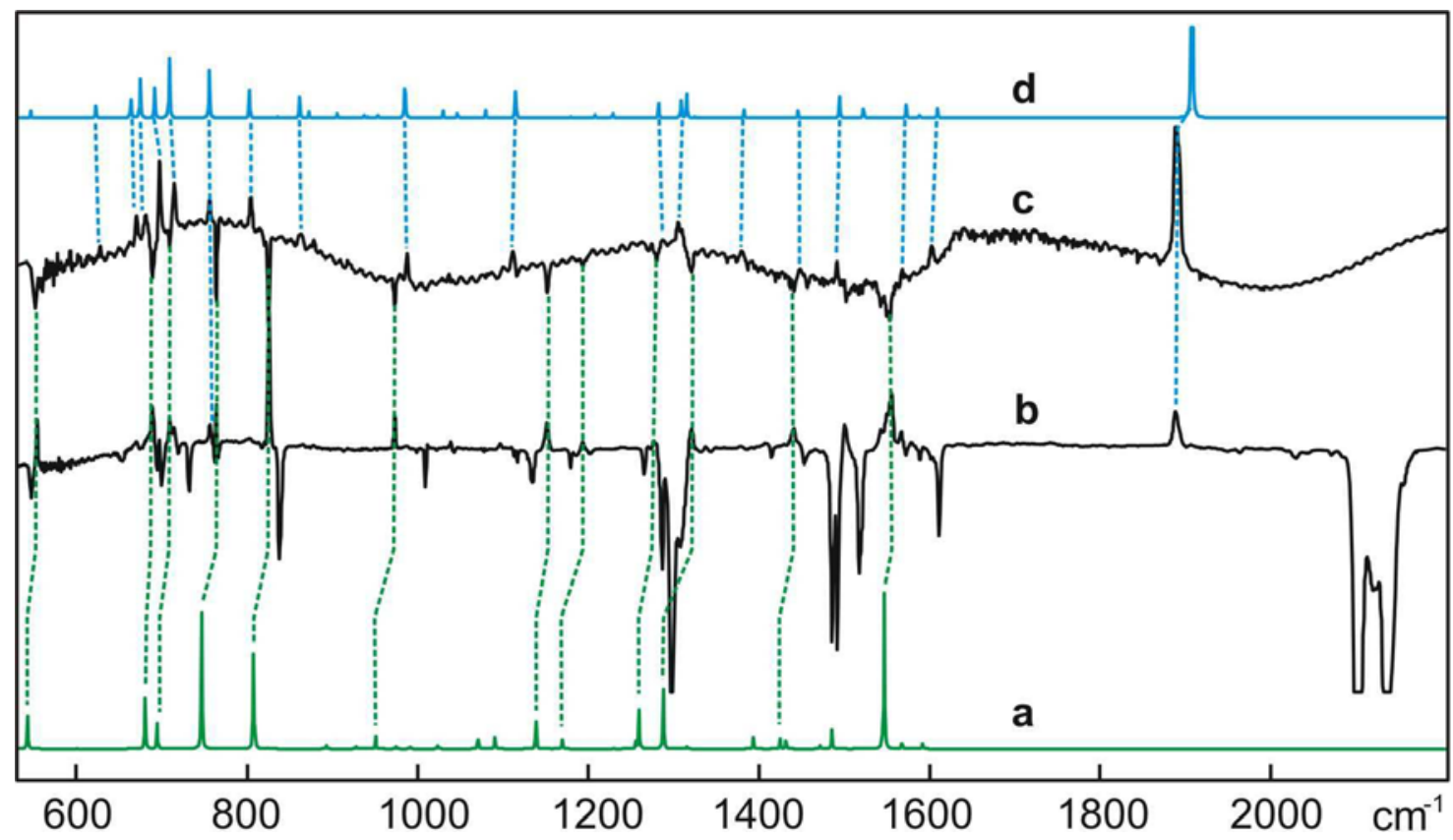

Figure S2. Difference IR spectra in for the photolysis of $p$-biphenylyl azide at $254 \mathrm{~nm}$, b, and of the resulting triplet nitrene at $>515 \mathrm{~nm}$, c. The peaks that rise in the first photolysis and decay in the second one correlate with those calculated for the triplet nitrene $(3 \mathbf{5}$, green spectrum a), whereas those which rise in the second photolysis correlate with the bands of the calculated spectrum of the keteneimine, spectrum d. 


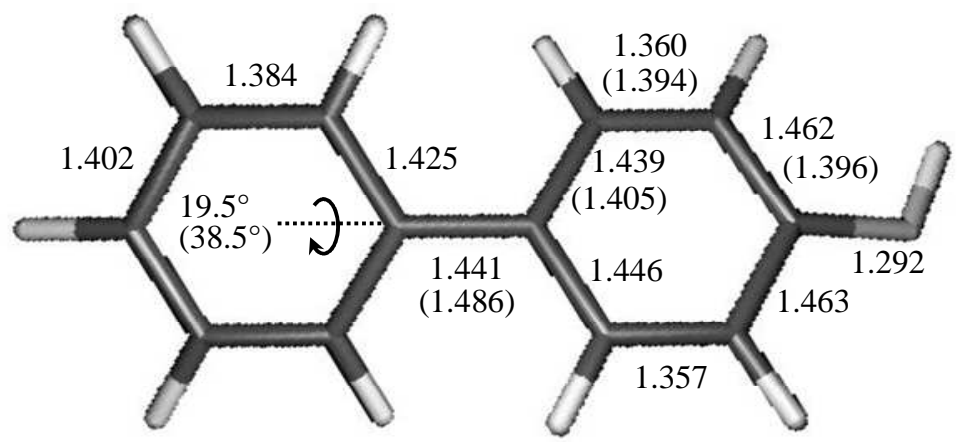

Figure S3. Bond lengths of the $p$-biphenylylnitrenium cation optimized by B3LYP/6-31G*. The values of the parent biphenyl (optimized by the same method) are shown in parenthesis. Full cartesian coordinates are listed on $\mathrm{p}$. S9
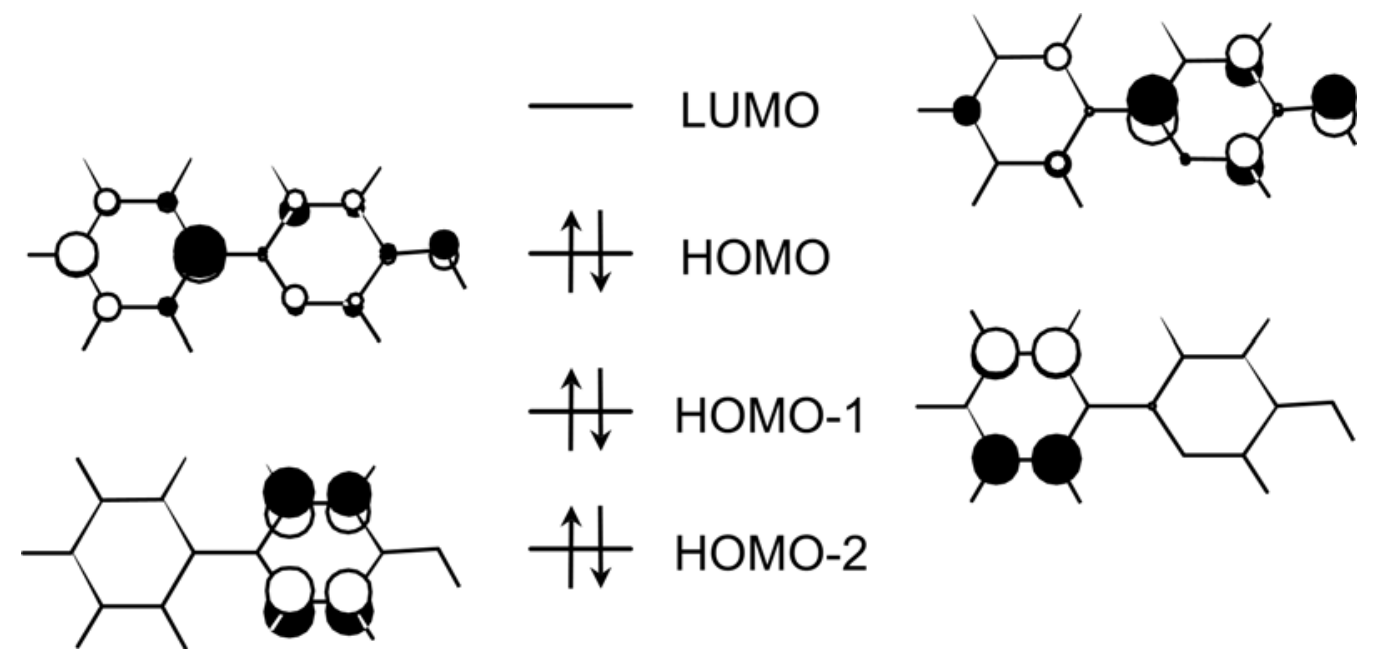

$\uparrow \downarrow$ HOMO-2

Figure S4. Molecular orbitals involved in the low lying electronic excitations of $p$-biphenylylnitrenium cation as described in Table 1 of the paper. 


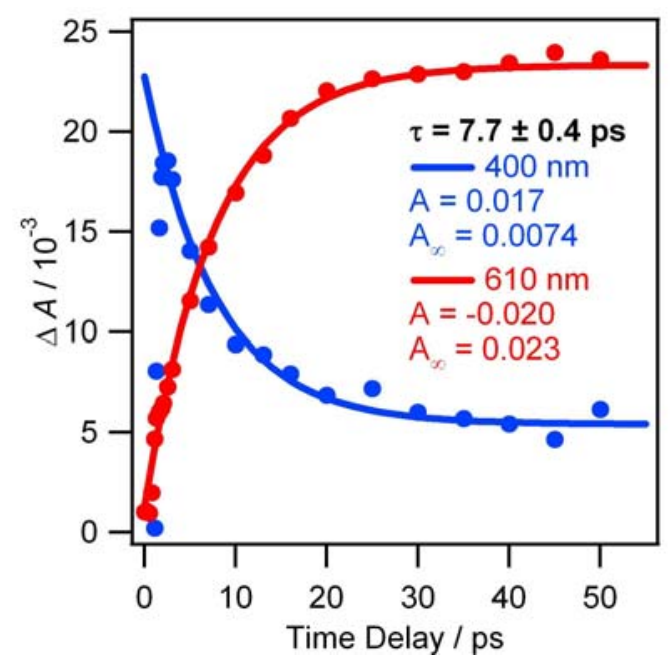

Figure S5. Kinetic traces of $o$-biphenylylnitrene and $o$-biphenylylnitrenium cation in $88 \%$ formic acid; excited by ultrafast LFP at $270 \mathrm{~nm}$ and probed at $400 \mathrm{~nm}$ and $610 \mathrm{~nm}$, respectively. The two kinetic traces were globally fitted to mono-exponential functions with the same time constant.

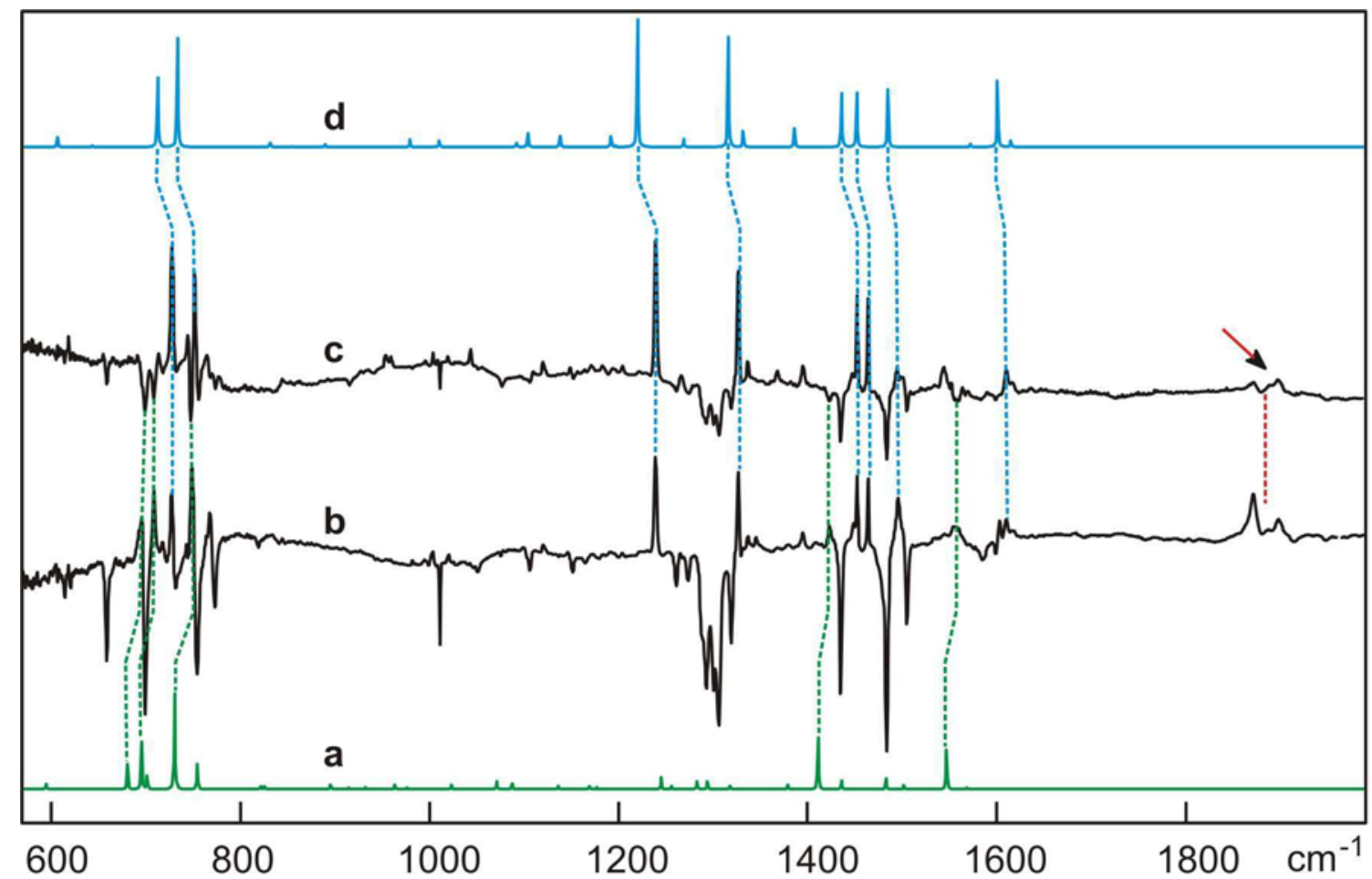

Figure S6. IR spectra of the $o$-biphenylyl azide in an Ar matrix after a short $254 \mathrm{~nm}$ photolysis, spectrum $\mathbf{b}$, and after bleaching by prolongued $254 \mathrm{~nm}$ photolysis, spectrum $\mathbf{c}$. Traces $\mathbf{a}$ and $\mathbf{d}$ are the simulated spectra of the $o$-biphenylyl nitrene $3 \mathbf{8}$ and carbazole $\mathbf{1 3}$, respectively, calculated by B3LYP/6-31G* and scaled by 0.97 . The red line points out a band that belongs presumably to ketenimine $\mathbf{1 0}$. 


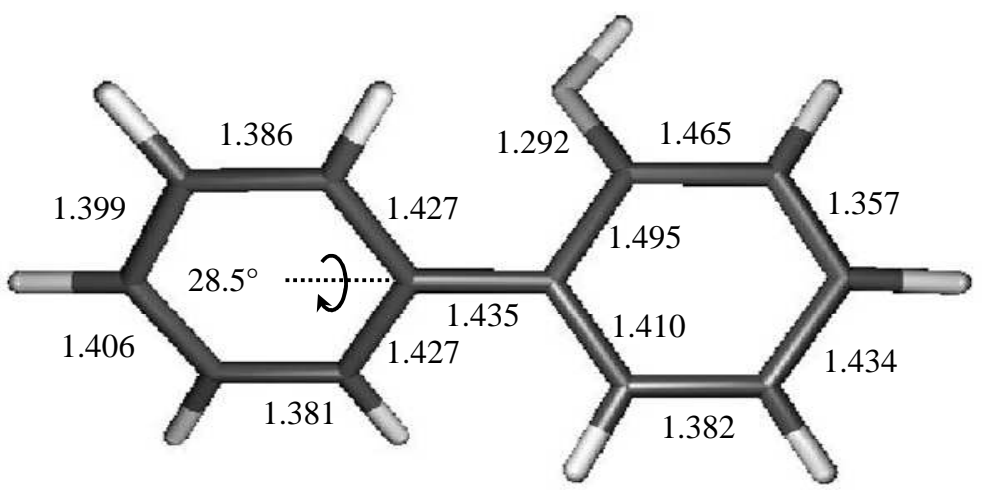

Figure S7. Optimized bondlenghts of $o$-biphenylylnitrenium cation by B3LYP/6-31G*. Full cartesian coordinates are listed on p. S10

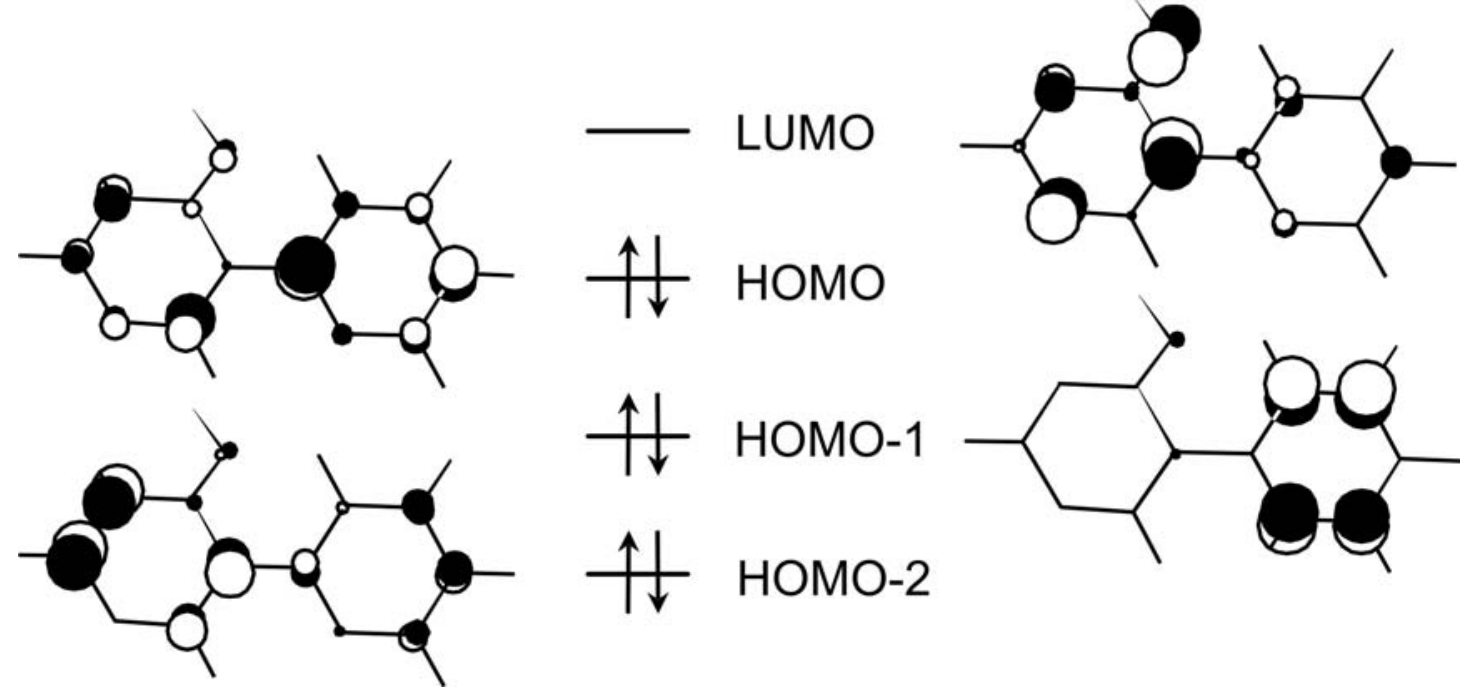

Figure S8. Molecular orbitals involved in low-lying electronic excitations of the $o$-biphenylylnitrenium cation as described in Table 2 of the paper. 


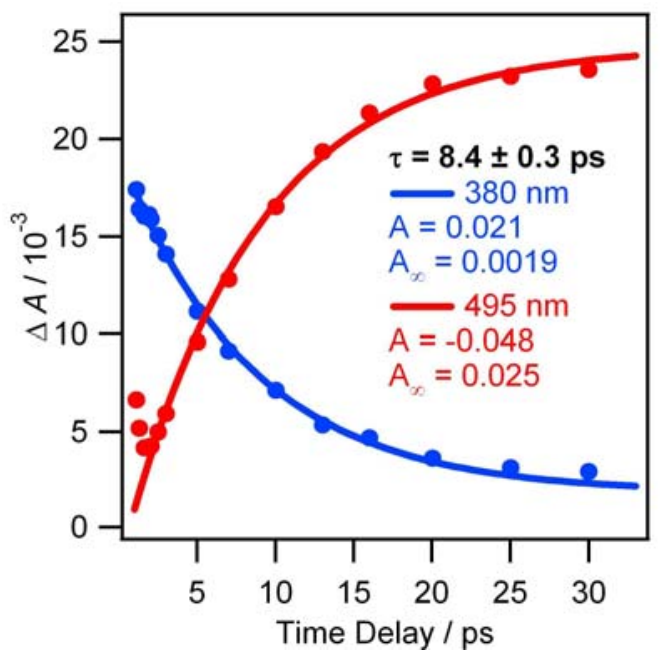

Figure S9. Kinetic traces of 1-naphthylnitrene and 1-naphthylnitrenium cation in $88 \%$ formic acid; produced by ultrafast LFP of 1-naphthyl azide at $270 \mathrm{~nm}$ and probed at $380 \mathrm{~nm}$ and $495 \mathrm{~nm}$, respectively. The two kinetic traces were globally fitted to mono-exponential functions with the same time constant.

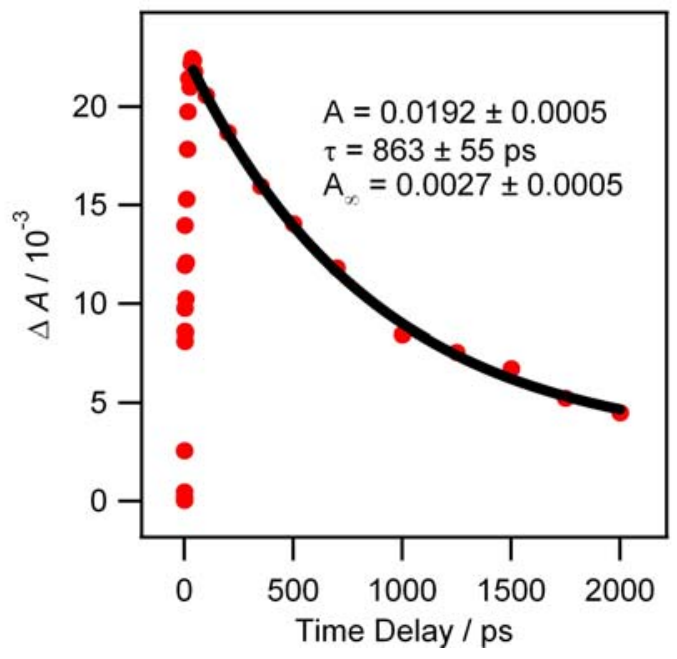

Figure S10. Kinetic traces of 1-naphthylnitrenium cation in $88 \%$ formic acid; excited by ultrafast LFP at $270 \mathrm{~nm}$ and probed at $495 \mathrm{~nm}$. 

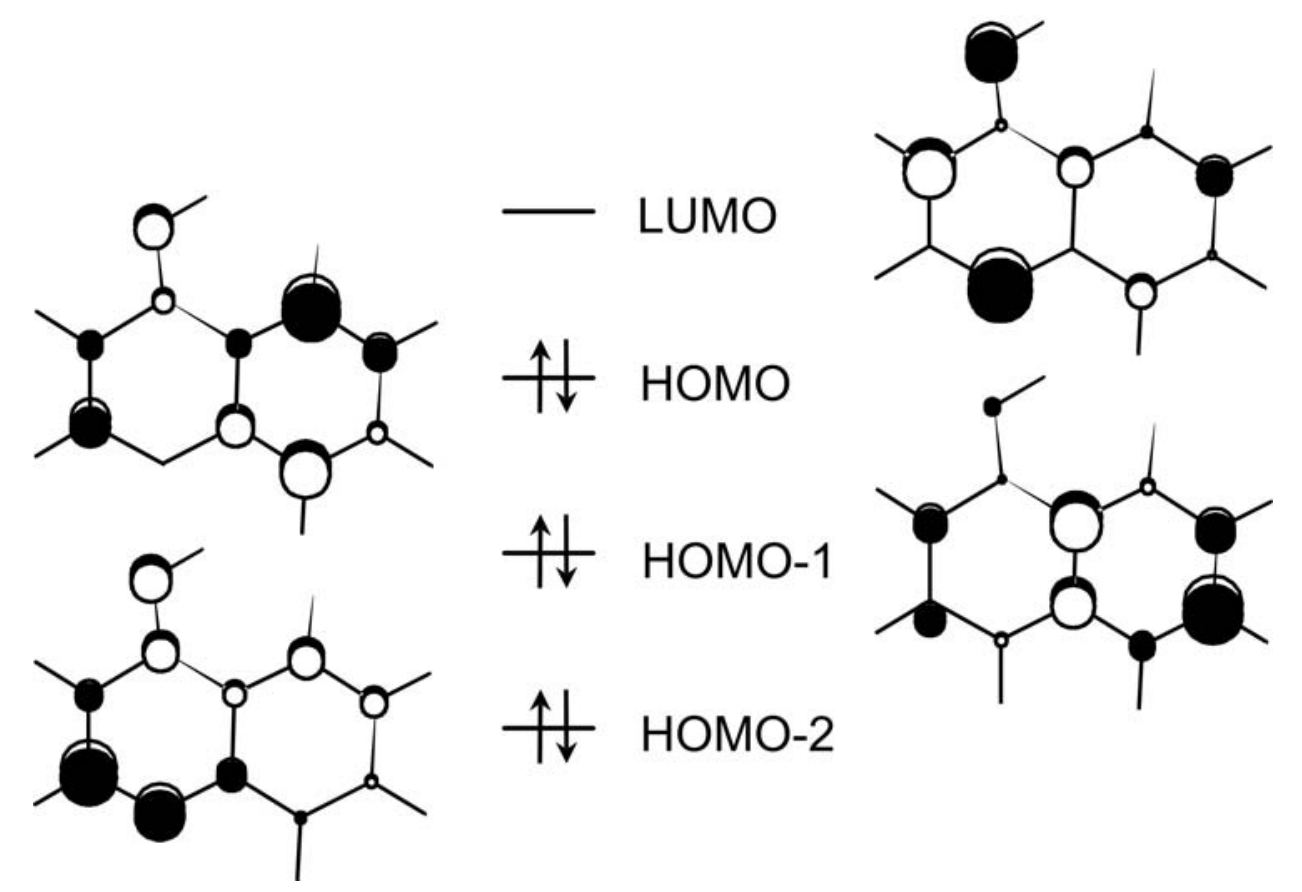

Af номо-1

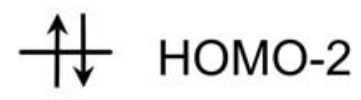

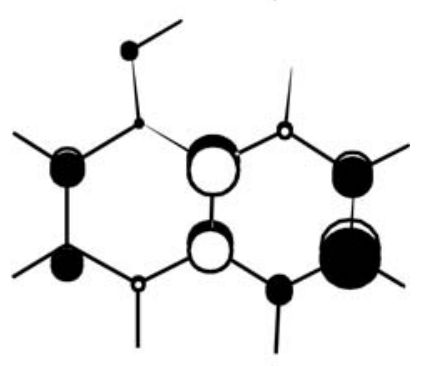

Figure S11. Molecular orbitals involved in the low energy electronic excitations of the 1-naphthyl nitrenium cation as described in Table 3 of the paper 


\section{Cartesian coordinates and energies of the $p$-biphenylnitrenium cation}

$\begin{array}{lrrr}6 & 3.223866 & -1.206885 & 0.222118 \\ 6 & 1.840287 & -1.207664 & 0.209911 \\ 6 & 1.112450 & -0.000798 & -0.000523 \\ 6 & 1.851446 & 1.198993 & -0.212633 \\ 6 & 3.234841 & 1.185058 & -0.226707 \\ 6 & 3.925607 & -0.014264 & -0.002815 \\ 1 & 3.764234 & -2.128589 & 0.408155 \\ 1 & 1.317716 & -2.133867 & 0.415538 \\ 1 & 1.336470 & 2.129650 & -0.417226 \\ 1 & 3.783619 & 2.101586 & -0.413711 \\ 1 & 5.011159 & -0.019476 & -0.003894 \\ 6 & -0.328074 & 0.008008 & 0.002261 \\ 6 & -1.062489 & 1.228670 & 0.208418 \\ 6 & -1.074317 & -1.212901 & -0.204023 \\ 6 & -2.421601 & 1.238324 & 0.219626 \\ 1 & -0.525139 & 2.147370 & 0.404714 \\ 6 & -2.431305 & -1.219507 & -0.216247 \\ 1 & -0.539769 & -2.133469 & -0.399959 \\ 6 & -3.188606 & 0.013166 & 0.002003 \\ 1 & -2.990188 & 2.144936 & 0.398750 \\ 1 & -2.980355 & -2.139278 & -0.398653 \\ 7 & -4.477217 & 0.109620 & 0.020600 \\ 1 & -4.929863 & -0.797401 & -0.146257\end{array}$

$\mathrm{SCF}$ Energy =

$-517.778068$

Sum of electronic and zero-point Energies=

$-517.590980$

Sum of electronic and thermal Energies=

$-517.580931$

Sum of electronic and thermal Enthalpies=

$-517.579986$

Sum of electronic and thermal Free Energies=

$-517.627170$ 


\section{Cartesian coordinates and energies of the o-biphenylnitrenium cation}

$\begin{array}{lrrr}6 & 2.873200 & 1.074846 & -0.518382 \\ 6 & 1.489191 & 1.016567 & -0.496442 \\ 6 & 0.821971 & -0.151351 & -0.020770 \\ 6 & 1.614410 & -1.258396 & 0.405343 \\ 6 & 2.992999 & -1.178853 & 0.398390 \\ 6 & 3.627218 & -0.014138 & -0.067798 \\ 1 & 3.370141 & 1.959011 & -0.902303 \\ 1 & 0.911025 & 1.840196 & -0.892024 \\ 1 & 1.135434 & -2.144252 & 0.806512 \\ 1 & 3.586406 & -2.011997 & 0.759119 \\ 1 & 4.711543 & 0.034715 & -0.088917 \\ 6 & -0.610147 & -0.238010 & 0.014881 \\ 6 & -1.289067 & -1.467558 & -0.109105 \\ 6 & -1.459634 & 0.981730 & 0.182201 \\ 6 & -2.665274 & -1.512932 & -0.227329 \\ 1 & -0.724716 & -2.386839 & -0.208393 \\ 6 & -2.902673 & 0.877883 & -0.048416 \\ 6 & -3.484409 & -0.336196 & -0.213640 \\ 1 & -3.488006 & 1.792283 & -0.014109 \\ 1 & -4.557763 & -0.433202 & -0.335390 \\ 7 & -0.896588 & 2.036749 & 0.670226 \\ 1 & -1.569166 & 2.807115 & 0.767225 \\ 1 & -3.145501 & -2.475824 & -0.376898\end{array}$

SCF Energy =

$-517.772331$

Sum of electronic and zero-point Energies=

$-517.585361$

Sum of electronic and thermal Energies=

$-517.575394$

Sum of electronic and thermal Enthalpies=

$-517.574449$

Sum of electronic and thermal Free Energies=

$-517.621131$ 


\section{Cartesian coordinates and energies of the 1 -naphthylnitrenium cation}

$\begin{array}{rrrr}6 & -2.036085 & -1.626221 & 0.027595 \\ 6 & -0.634151 & -1.671228 & -0.025996 \\ 6 & 0.093401 & -0.490232 & -0.018044 \\ 6 & -0.603383 & 0.762248 & 0.045123 \\ 6 & -2.026518 & 0.781075 & 0.098723 \\ 6 & -2.732580 & -0.407506 & 0.089745 \\ 1 & -2.592857 & -2.558326 & 0.020671 \\ 1 & -0.111125 & -2.619688 & -0.073655 \\ 6 & 1.575860 & -0.476244 & -0.072881 \\ 6 & 0.131210 & 1.955503 & 0.053204 \\ 1 & -2.543083 & 1.734850 & 0.146295 \\ 1 & -3.816125 & -0.403045 & 0.130263 \\ 6 & 1.552069 & 1.992645 & 0.001379 \\ 6 & 2.255040 & 0.824187 & -0.059520 \\ 1 & -0.409396 & 2.898332 & 0.101350 \\ 1 & 2.060424 & 2.950494 & 0.010898 \\ 1 & 3.341285 & 0.828900 & -0.099838 \\ 7 & 2.200493 & -1.602423 & -0.129707 \\ 1 & 3.218250 & -1.479921 & -0.163998\end{array}$

SCF Energy =

$-440.360369$

Sum of electronic and zero-point Energies=

$-440.207335$

Sum of electronic and thermal Energies=

$-440.199379$

Sum of electronic and thermal Enthalpies=

$-440.198435$

Sum of electronic and thermal Free Energies=

$-440.240127$ 